Review

\title{
Recent Advances in Perylene Diimide-Based Active Materials in Electrical Mode Gas Sensing
}

\author{
Salman Ali ${ }^{1} \mathbb{D}$, Akhil Gupta ${ }^{1}$, Mahnaz Shafiei ${ }^{2, * \mathbb{C}}$ and Steven J. Langford ${ }^{1, *}$ \\ 1 Department of Chemistry and Biotechnology, Faculty of Science, Engineering and Technology, \\ Swinburne University of Technology, Hawthorn, VIC 3122, Australia; salmanali@swin.edu.au (S.A.); \\ akhilgupta@swin.edu.au (A.G.) \\ 2 School of Software and Electrical Engineering, Faculty of Science, Engineering and Technology, \\ Swinburne University of Technology, Hawthorn, VIC 3122, Australia \\ * Correspondence: mshafiei@swin.edu.au (M.S.); sjlangford@swin.edu.au (S.J.L.)
}

Citation: Ali, S.; Gupta, A.; Shafiei, M.; Langford, S.J. Recent Advances in Perylene Diimide-Based Active Materials in Electrical Mode Gas Sensing. Chemosensors 2021, 9, 30. https://doi.org/10.3390/ chemosensors 9020030

Academic Editor: Pietro Salvo Received: 19 November 2020 Accepted: 26 January 2021 Published: 1 February 2021

Publisher's Note: MDPI stays neutral with regard to jurisdictional claims in published maps and institutional affiliations.

Copyright: (c) 2021 by the authors. Licensee MDPI, Basel, Switzerland. This article is an open access article distributed under the terms and conditions of the Creative Commons Attribution (CC BY) license (https:/ / creativecommons.org/licenses/by/ $4.0 /)$.

\begin{abstract}
This review provides an update on advances in the area of electrical mode sensors using organic small molecule $n$-type semiconductors based on perylene. Among small organic molecules, perylene diimides (PDIs) are an important class of materials due to their outstanding thermal, chemical, electronic, and optical properties, all of which make them promising candidates for a wide range of organic electronic devices including sensors, organic solar cells, organic field-effect transistors, and organic light-emitting diodes. This is mainly due to their electron-withdrawing nature and significant charge transfer properties. Perylene-based sensors of this type show high sensing performance towards various analytes, particularly reducing gases like ammonia and hydrazine, but there are several issues that need to be addressed including the selectivity towards a specific gas, the effect of relative humidity, and operating temperature. In this review, we focus on the strategies and design principles applied to the gas-sensing performance of PDI-based devices, including resistive sensors, amperometric sensors, and operating at room temperature. The device properties and sensing mechanisms for different analytes, focusing on hydrazine and ammonia, are studied in detail, and some future research perspectives are discussed for this promising field. We hope the discussed results and examples inspire new forms of molecular engineering and begin to open opportunities for other rylene diimide classes to be applied as active materials.
\end{abstract}

Keywords: $n$-type organic molecules; perylene diimide; hydrazine; ammonia; sensors

\section{Introduction}

The increase in globalization, digitization, and the rapid production techniques of industry come with the need to be able to measure our environment, either local or more global, to ensure safe working and living environments for our communities to prosper. In particular, the monitoring and detection of toxic and harmful gases, air pollutants, and explosives are an essential need in industries such as pharmaceuticals, propulsion systems, fertilizers, renewable energy, and manufacturing, as well as in everyday life including the need to safely travel by air. Sensors are the primary devices used for the detection and monitoring of the toxic, explosive, and flammable analytes present in our surroundings, and a great deal of attention has been paid to the development of various types of gas sensors, including electrical, optical, acoustic, and fluorescent [1-9]. Major analytes include hydrazine $\left(\mathrm{N}_{2} \mathrm{H}_{4}\right)$, ammonia $\left(\mathrm{NH}_{3}\right)$, hydrogen $\left(\mathrm{H}_{2}\right)$, hydrogen peroxide $\left(\mathrm{H}_{2} \mathrm{O}_{2}\right)$, nitrogen dioxide $\left(\mathrm{NO}_{2}\right)$, methane $\left(\mathrm{CH}_{4}\right)$, and volatile organic compounds (VOCs), all of which cause adverse effects on human and environmental health [10-12]. The commercially available sensors are primarily based on inorganic materials [13], and, although market leading, they suffer from a number of disadvantages, including complex fabrication techniques, a lack of selectivity, the need for a high working temperature, and above all, high-costs [14,15]. Therefore, it is still important to develop new and suitable alternatives to fabricate gas 
sensors that are reliable, low-cost, stable at room temperature, and have a high degree of selectivity towards the desired analyte.

Over the past few years, organic semiconductors have gained some attention in gas-sensing applications, primarily due to their unique properties, including solution processability, low-cost fabrication, room temperature (RT) operation, ease of integration, and scalable and straightforward synthetic strategies [16]. Along with the development of organic field-effect transistors (OFETs), the design and synthesis of novel organic materials has provided a vast material library for electrical gas-sensing applications, e.g., pigments and dyes such as phthalocyanines [17-20], perylene diimide derivatives [21-24], and conjugated polymers [25-31]. There are two main types of organic semiconductors: the so-called $p$ - and $n$-types. The $p$-type organic semiconductors are more widely applied in gassensing applications [32] compared to their $n$-type counterparts. This is primarily because, when $p$-type organic materials are exposed to oxidizing gases such as $\mathrm{NO}_{2}$, an increase in conductivity occurs, whereas the reverse happens for reducing gases, such as $\mathrm{NH}_{3}$ and $\mathrm{H}_{2}$; thus, a positive response result is attained over a reduction in response, which could be interpreted in other ways, such as device failure or not providing a measurable linear response past a certain level. A variety of $p$-type organic materials, including pentacene, phthalocyanines, and thiophene, have become of interest, and they have all been used for gas-sensing applications [32]. The $n$-type materials continue to have limited utility for gas-sensing applications, mainly due to their instability in the air [32]. However, there are several $n$-type organic materials that have been designed and developed for gas-sensing applications [33] by incorporating a variety of electron-withdrawing groups, e.g., cyano $(\mathrm{CN})$, fluoro $(\mathrm{F})$, and chloro $(\mathrm{Cl})$ within their structure. Due to the inherent electron-deficient nature of $n$-type materials, an increase in conductivity occurs when they are exposed to reducing gases, and the opposite happens for oxidizing gases [22,23,34,35]. Hence, the development of a library of organic semiconductors that demonstrate specific properties for specific analytes and gases, with specific responses to reducing or oxidizing gases, could be an important advance to the field. In this review, we elaborate on the chemistry of perylene diimides as an example of the $n$-type class that led to its use in sensor development.

Perylene diimide (PDI), as shown in Figure 1, is an $n$-type organic semiconductor discovered by Kardos in 1913 [36]. Initially used as a textile dye, this high-performing pigment comes in red, violet, and near-black shades [37]. PDIs possess a high thermal stability and photostability under ambient conditions [38], making them viable for self-assembly processing and applications in various electronic devices [39]. Several PDI molecules have been prepared into well-shaped supramolecular nanostructures; these achievements have also encouraged the area of the self-assembly of many other $n$-type organic semiconductor molecules [40]. The existence of electron-withdrawing imide fragments in PDIs permits them to be simply reduced chemically or electrochemically, forming radical anions, yet remaining stable to oxidation [41]. Their resistance to oxidation is the main reason why PDIs generally act as stable $n$-type organic materials [42]. Together with their additional properties, including facile structural functionalization, excellent light-absorption in the visible region, and near-unity fluorescence quantum yields in the molecular state, PDIs have been known as appealing candidates for preparing organic optoelectronic materials and devices, such as organic photovoltaics (OPVs), organic field effect transistors (OFETs), dye lasers, organic light-emitting diodes (OLEDs), and sensors [22,42-44]. The well-shaped 1D nanostructures of PDIs can be prepared via supramolecular self-assembly procedures [44]. This $1 \mathrm{D}$ self-assembly is mostly governed by the intrinsic $\pi-\pi$ stacking interaction between the aromatic perylene planes, which support the $1 \mathrm{D}$ growth of assembly in cooperation with other intermolecular noncovalent interactions. The 1D nanostructures of PDIs display excellent optical and electronic properties along the $1 \mathrm{D} \pi-\pi$ stacking direction, which offers great potential for electronic device application like OPVs and sensors $[44,45]$. 


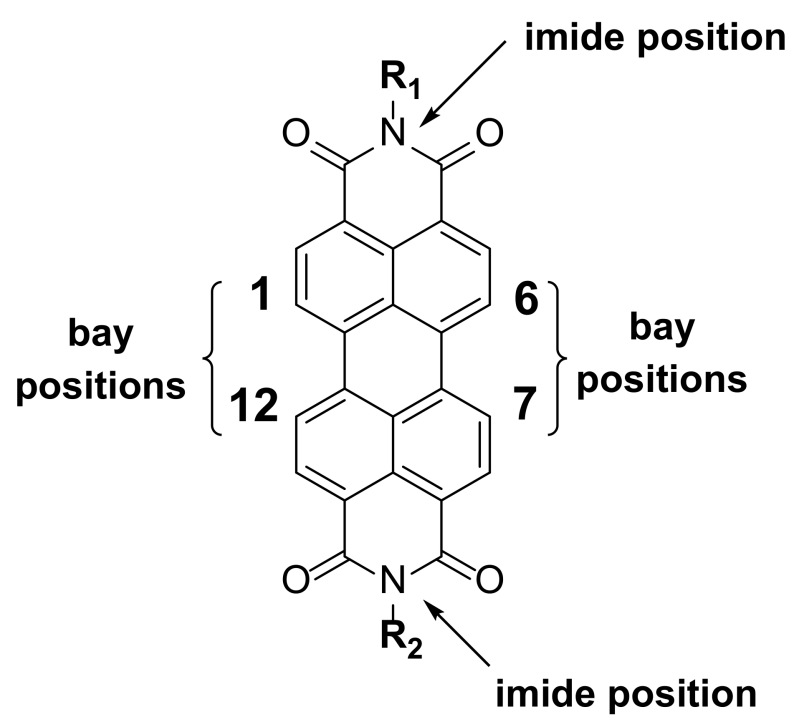

Figure 1. Structure of perylene diimide (PDI) core.

PDI and its derivatives have been studied as active materials in numerous organic electronic devices such as OPVs, OLEDs, and OFETs [36,46,47]. As is the focus of this review, PDI derivatives have also been widely used in gas-sensing applications, mainly due to their electron-deficient nature, desired self-assembled and crystal structures, and high chemical and thermal stabilities [36]. To improve the sensing performance of PDI-based sensors, research has focused on the molecular modification of PDI [21,22,48-50]. The modifications highlighted in this review within the PDI structure can be achieved through either substitution on nitrogen atoms or via incorporating aryl and/or alkyl substituents on the core and, in particular, the bay positions [41,51,52]. PDIs generated through imide nitrogen substitution usually possess similar optoelectronic properties because the electron density nodes in the lowest unoccupied molecular orbital (LUMO) and the highest occupied molecular orbital (HOMO) levels at imide positions reduce the coupling between the PDI unit and the imide substituents to a minimum [41]. In this respect, this is an excellent way of modification for processability or the introduction of connectors. PDIs obtained through substitution at the core are generally highly conjugated targets, and, depending upon the substitution, the optical band gap, crystal structure, absorption profile, and solubility of the target can be altered $[53,54]$. Moreover, such substitutions may help to minimize the $\pi-\pi$ overlap between aggregating naphthalene subunits to improve the sensing performance of the resulting devices $[43,55]$. The structure modification through imide or core positions can affect the morphology and self-assembly of the PDIs, which can improve the sensing performance $[22,56]$.

This review presents a summary of the reports on PDI-based electrical mode gas sensors that have been developed over the past decade. These sensors include resistive and amperometric devices that have been tested and evaluated towards reductive gases like hydrazine and ammonia at RT. We begin by describing PDI incorporation into electrical mode gas sensors, their configuration, and their sensing mechanisms. We then critically review reports on sensors incorporating PDIs for hydrazine, ammonia, and some other analytes. Finally, we describe the future outlook of PDIs and other rylene diimides as appropriate active components for electrical gas sensors.

\section{Electrical Gas Sensors and Sensing Mechanism}

Electrical gas sensors have been extensively studied, reported, and utilized, mainly because of their ease of processing and fabrication, portability, low-cost, and compatibility with various standard electronics [57]. An electrical gas sensor usually consists of two major components: the active material and the transducer. Generally, the mechanism of electrical gas sensors using organic materials is based on gas adsorption/desorption at the active 
material surface. A charge-transfer complex between the active layer and an analyte is formed, thus leading to a change in the charge carrier mobility of the sensing material and. hence, in the electrical response through conductivity, resistivity, and current $[28,58,59]$. This mechanism of adsorption may contain either chemical or weak interactions, i.e., chemisorption or physisorption, depending upon the chemical properties of both the sensing materials and the analyte [60]. To bring the sensor to its initial state, the target gas is removed from the testing chamber and air or nitrogen as a reference gas is introduced. The sensitivity or response of active materials mainly depends on two factors: (1) a high surface area, which can provide effective diffusion of the gas molecules, and (2) the chemical nature of the active materials, such as molecular packing, redox potential, and energy level, which are associated with the formation of charge carriers and efficient transport into the active materials [58]. As an $n$-type organic semiconductor, PDI can accept electrons from the electron donor gas, such as ammonia and hydrazine, via donor-acceptor complexation. Thus, the electrons can be efficiently transported through $\pi$-electron delocalization along the long-axis of perylene dyes and ultimately lead to a measurable increase in resistance or current $[21,22,58]$.

Applying standard electronic devices such as resistors, capacitors, and field-effect transistors (FETs) allows the variations in the sensors active layer's physical properties to be recorded in the form of change in resistance or current $(\Delta R$ or $\Delta I)$, capacitance $(\Delta C)$, and voltage $(\Delta V)$, respectively, [61-63] as shown in Figure 2. Electrical gas sensors that record these gas-solid interactions mainly take the three device configurations of FET, capacitor, and chemiresistor (amperometric and resistive) [64-66].

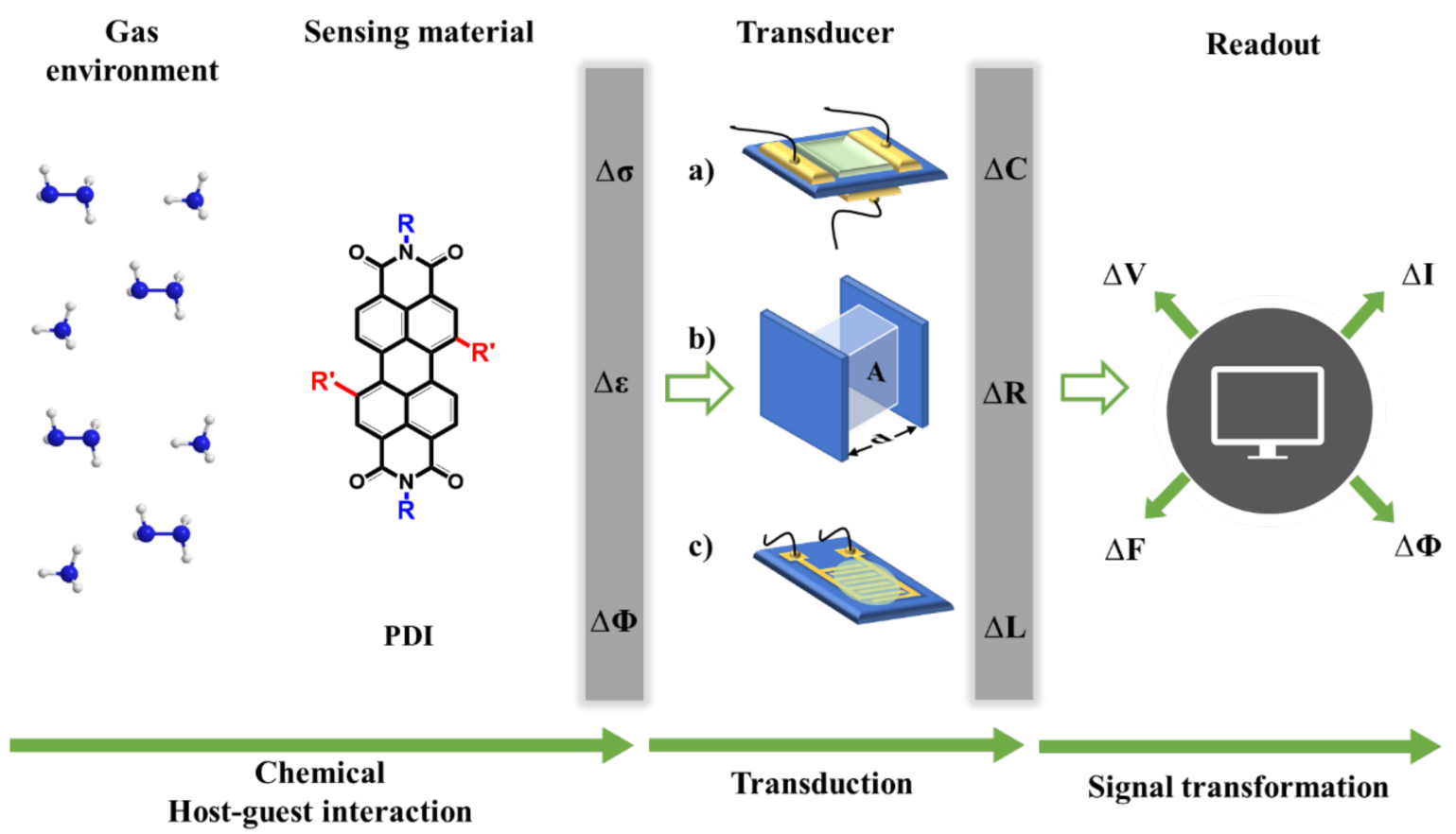

Figure 2. Schematic diagram illustrating the major components required to evaluate an electrical mode gas-sensing mechanism. The transducers are (a) FETs, (b) capacitors and (c) chemiresistors. Analytes interact with the sensing material changes some of its physical properties such as conductivity (s), work function (j), and permittivity (e). The transducer converts one of these physical quantities into the variation of its electric parameters such as capacitance, $C$, and resistance, $R$. Finally, the circuit to which the sensor is connected gives rise to the sensing electrical signal that can be in either current $(I)$ or voltage $(V)$, and each can be measured in frequency $(F)$ and phase $(\Phi)[67]$.

In 1975, Lundstrom developed the core components of an FET-based gas sensor for the first time [68]. Generally, an FET contains two electrodes (the source and the drain), connected by a sensing layer as the channel, and a gate electrode usually located on the underside of the substrate (Figure 2a). When a source-drain voltage is applied, current 
flows through the channel, which is matched through the charge carriers by applying a gate voltage. This provides supplementary ways to control the current response in the sensing layer upon interacting with a target analyte. Outputs other than variations in channel current, such as the threshold voltage and sub-threshold swing, can also be used to reflect the sensing process [69]. Despite their complex structure and fabrication, these advantages make FETs more stable and reliable for gas sensing compared to chemiresistors. PDIs and other organic materials are being considered for FETs where flexibility, low processing temperatures, and print deposition are desired or additional chemical functionality to create the chemical selectivity needed for functioning gas sensors is required. As PDIs and other organic molecules have inferior mobilities than inorganic materials, they need higher drain and gate voltages to produce viable currents.

Capacitive-type sensors are mainly used for molecular detection including large entities such as DNA [70], biomolecules [71], smaller molecules related to humidity [72], and general gases [73]. In most cases, a capacitive-type sensor comprises a layer of active material sandwiched between two parallel electrodes (Figure 2b). The capacitance of the sensor is usually expressed as $C=\varepsilon_{0} \varepsilon_{r} A / d$, where $\varepsilon_{0}$ is the permittivity in vacuum, $\varepsilon_{r}$ is the relative permittivity of the active material, $A$ is the capacitor area, and $d$ is the gap between the electrodes [74]. Gas or humidity adsorption on the active material alters $\varepsilon_{r}$ and, as a result, changes the sensor capacitance. For the case of polymer-based active materials, gas-induced swelling and the subsequent alteration of $d$ or $A$ between the electrodes can also cause a change in the capacitance [75]. The capacitor set-up also permits the measurement of the change in material impedance, which is associated with both the resistive and capacitive variations in response to target analyte adsorption, typically in the range of zero to several megahertz [76]. PDIs and other organic molecules have been used in capacitive-type sensors for humidity and gas-sensing applications. PDI-based humidity sensors have only shown good sensitivity in high-humidity environments and are unable to show notable responses below $60 \%$ RH [72].

To date, the majority of PDI-based sensors have been developed as chemiresistive, i.e., resistive or amperometric, configurations, as shown in Figure 2c. A chemiresistor usually comprises interdigitated electrodes (IDEs) linked with a sensing material deposited onto an insulating substrate [77]. The resistance, i.e., current, of the sensing material changes upon exposure to the target analytes. Chemiresistive sensors comprise one of the most extensively used device structures for gas-sensing applications due to their simplicity, compatibility with the conventional direct current (DC) circuits, low-cost, predictable electrical properties, ease of high accuracy measurements [77], and suitability when speedy prototyping is essential. The simple design and operation of this type of device renders it appealing starting platforms for studying the chemical response of novel materials. Despite their simple setup, chemiresistors are restricted by their single type of output, which is easily influenced by environmental perturbations.

To analyze the general performance of a gas sensor against others, a number of parameters extracted from static and dynamic measurements are needed [78,79]. Critical parameters include sensitivity, selectivity, stability, hysteresis, response and recovery time, the limit of detection (LOD), and working temperature. Ideally, a gas sensor should possess a high sensitivity to the target gas with a linear response, quick response and recovery, high selectivity, low hysteresis, low LOD, and long-term stability. One of the disadvantages of organic materials is their perceived long-term instability when compared to inorganic materials. 


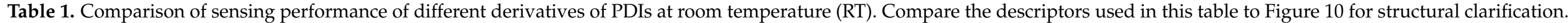

\begin{tabular}{|c|c|c|c|c|c|c|c|c|c|}
\hline 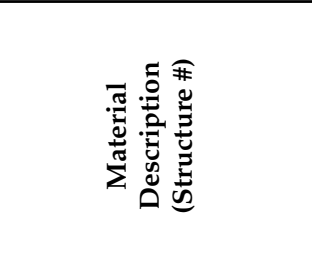 & 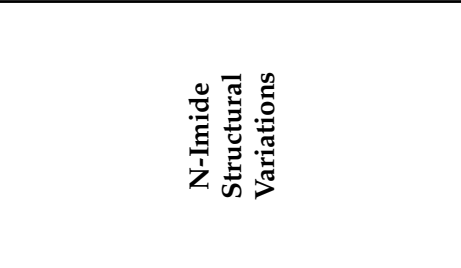 & ن & 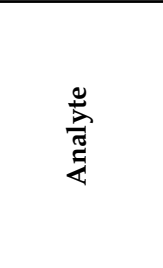 & 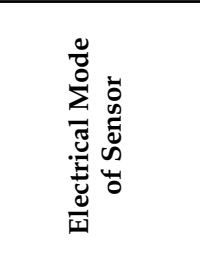 & 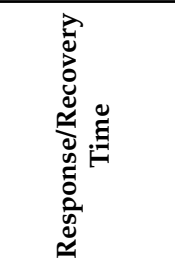 & 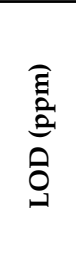 & 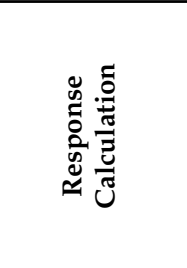 & 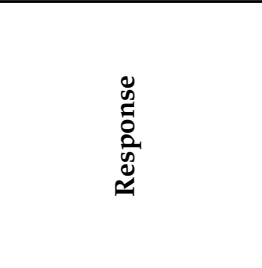 & $\ddot{\cong}$ \\
\hline $\begin{array}{l}\text { PDI-nanotubes } \\
\text { PDI-nanorods } \\
\text { (1) }\end{array}$ & Tertiary amine-iodide complex & NA & Hydrazine & Resistive & $\begin{array}{l}180 \mathrm{~s} /{ }^{\mathrm{a}} \\
102 \mathrm{~s} /{ }^{\mathrm{a}}\end{array}$ & 10 & $R / R_{o}$ & $\begin{array}{c}100 \\
1000 \\
\text { at } 10 \mathrm{ppm}\end{array}$ & [48] \\
\hline $\begin{array}{l}\text { PDI-single nanoribbon } \\
\text { PDI-nanofiber bundle } \\
\text { (2) }\end{array}$ & Sugar-based achiral alkyl chains & NA & Hydrazine & Resistive & $\begin{array}{l}300 \mathrm{~s} /{ }^{\mathrm{a}} \\
400 \mathrm{~s} /{ }^{\mathrm{a}}\end{array}$ & 10 & $R / R_{o}$ & $\begin{array}{c}10^{4} \\
100 \\
\text { at } 10 \mathrm{ppm}\end{array}$ & [56] \\
\hline $\begin{array}{c}\text { PDI-OBAG } \\
\text { PDI-DBAG } \\
\text { PDI-HBAG } \\
\text { (3) }\end{array}$ & $\begin{array}{l}\text { Sugar-based achiral and n-alkyl } \\
\text { chains }\end{array}$ & NA & Hydrazine & Amperometric & $\begin{array}{l}350 \mathrm{~s} /{ }^{\mathrm{a}} \\
350 \mathrm{~s} /{ }^{\mathrm{a}} \\
350 \mathrm{~s} /{ }^{\mathrm{a}}\end{array}$ & 10 & $I / I_{o}$ & $\begin{array}{c}2.5 \times 10^{4} \\
5.2 \times 10^{4} \\
4 \times 10^{4} \\
\text { at } 10 \mathrm{ppm}\end{array}$ & [80] \\
\hline $\begin{array}{c}\text { PDI-C }_{12} \\
\text { PDI-ClC }_{12} \\
\text { PDI-ClC }_{4} \mathrm{~F}_{7} \\
\quad(4)\end{array}$ & Dodecyl and perfluorobutyl groups & $\mathrm{H}$ and $\mathrm{Cl}$ & Hydrazine & Resistive & $\begin{array}{l}160 \mathrm{~s} /{ }^{\mathrm{a}} \\
600 \mathrm{~s} /{ }^{\mathrm{a}} \\
600 \mathrm{~s} /{ }^{\mathrm{a}}\end{array}$ & 8 & $R / R_{o}$ & $\begin{array}{c}100 \\
10^{4} \\
10^{4} \\
\text { at } 10 \mathrm{ppm}\end{array}$ & [22] \\
\hline $\begin{array}{l}\text { PDI-d } \\
\text { (5) }\end{array}$ & $n$-Ethylhexyl & $\begin{array}{c}\text { Substituted } \\
\text { acetylenes }\end{array}$ & Hydrazine & Resistive & $4 \mathrm{~s} / 4 \mathrm{~s}$ & 0.7 & $\Delta R / R_{o} \times 100$ & $\begin{array}{l}46.67 \% \\
\text { at } 10 \mathrm{ppm}\end{array}$ & [81] \\
\hline $\begin{array}{c}\text { PDI-Bp }{ }_{2} \mathrm{C}_{10} \\
\text { PDI-C }_{10} \\
\text { PDI-Br }_{2} \mathrm{C}_{10} \\
\text { (6) }\end{array}$ & $\begin{array}{l}\text { n-Alkyl substituents with chiral } \\
\text { center }\end{array}$ & $\begin{array}{l}\mathrm{H}, \mathrm{Br} \text {, and } \\
\text { aryloxy } \\
\text { substituents }\end{array}$ & Hydrazine & Amperometric & $\begin{array}{l}450 \mathrm{~s} / 150 \mathrm{~s} \\
300 \mathrm{~s} / 350 \mathrm{~s} \\
700 \mathrm{~s} / 200 \mathrm{~s}\end{array}$ & $\begin{array}{c}0.75 \\
0.75 \\
1\end{array}$ & $I / I_{0}$ & $\begin{array}{c}10^{4} \\
10^{3} \\
10^{2} \\
\text { at } 10 \mathrm{ppm}\end{array}$ & [82] \\
\hline $\begin{array}{l}\text { PDI-DEY } \\
\text { PDI-DSPY } \\
\text { PDI-DTPY } \\
\text { PDI-DFPY } \\
\text { (7) }\end{array}$ & n-Alkyl substituents & $\begin{array}{l}\text { Substituted } \\
\text { acetylenes }\end{array}$ & Hydrazine & Amperometric & $\begin{array}{l}800 \mathrm{~s} /{ }^{\mathrm{a}} \\
800 \mathrm{~s} /{ }^{\mathrm{a}} \\
750 \mathrm{~s} /{ }^{\mathrm{a}} \\
800 \mathrm{~s} /{ }^{\mathrm{a}}\end{array}$ & 10 & $I / I_{0}$ & $\begin{array}{c}10^{5} \\
\sim 10^{4} \\
\sim 10^{4} \\
10^{4} \\
\text { at } 10 \mathrm{ppm}\end{array}$ & [58] \\
\hline $\begin{array}{l}\text { PDI-ClC }_{10} \\
\text { PDI-CNC } \\
\text { (8) }\end{array}$ & $\begin{array}{l}\text { n-Alkyl substituents with chiral } \\
\text { center }\end{array}$ & $\mathrm{CN}$ and $\mathrm{Cl}$ & Hydrazine & Amperometric & $\begin{array}{l}350 \mathrm{~s} / 350 \mathrm{~s} \\
350 \mathrm{~s} / 350 \mathrm{~s}\end{array}$ & $\begin{array}{l}1 \\
2\end{array}$ & $I / I_{o}$ & $\begin{array}{c}10^{4} \\
\sim 10^{3} \\
\text { at } 10 \mathrm{ppm}\end{array}$ & [34] \\
\hline $\begin{array}{l}\text { PDI-pyrimidine } \\
\text { (9) }\end{array}$ & Fluorinated alkyl substituents & $\begin{array}{l}\text { Phenyl and } \\
\text { pyrimidine }\end{array}$ & Hydrazine & Resistive & $23.2 \mathrm{~s} / 35.4 \mathrm{~s}$ & 0.1 & $\Delta R / R_{o} \times 100$ & $90.72 \%$ at $100 \mathrm{ppm}$ & {$[50]$} \\
\hline
\end{tabular}


Table 1. Cont.

\begin{tabular}{|c|c|c|c|c|c|c|c|c|c|}
\hline 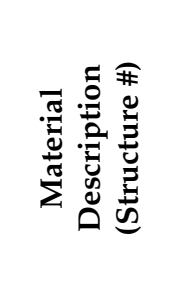 & 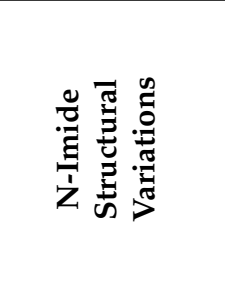 & ن⿺辶寸 & $\frac{\stackrel{0}{\lambda}}{\mathfrak{Z}}$ & 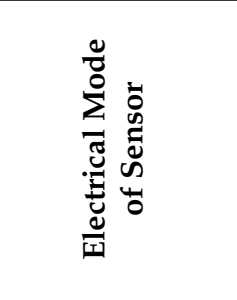 & 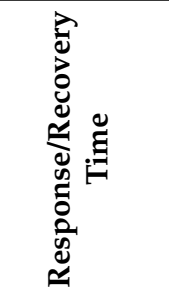 & 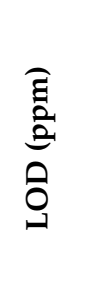 & 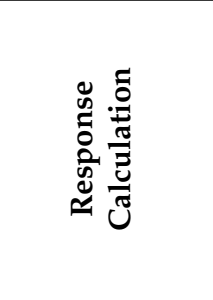 & 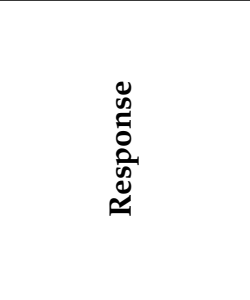 & $\overleftrightarrow{\mathscr{\Xi}}$ \\
\hline $\begin{array}{l}\text { PDI-PH } \\
\text { PDI-TPH } \\
\text { PDI-OPH } \\
\quad(10)\end{array}$ & Cyclohexane & $\begin{array}{c}\text { Aryloxy } \\
\text { substituents }\end{array}$ & Hydrazine & Amperometric & $\begin{array}{l}116 s / 19 s \\
163 s / 52 s \\
170 s / 58 s\end{array}$ & $\begin{array}{l}0.6 \\
0.5 \\
0.5\end{array}$ & $I / I_{O}$ & $\begin{array}{c}130 \\
520 \\
1800 \\
\text { at } 5 \mathrm{ppm}\end{array}$ & [83] \\
\hline $\begin{array}{l}\text { PDI-OT } \\
\text { PDI-ROT } \\
\text { PDI-SOT } \\
\quad(11) \\
\end{array}$ & n-Alkyl chains & $\begin{array}{l}\text { Substituted } \\
\text { acetylenes }\end{array}$ & Hydrazine & Amperometric & $\begin{array}{l}400 \mathrm{~s} /{ }^{\mathrm{a}} \\
350 \mathrm{~s} /{ }^{\mathrm{a}} \\
360 \mathrm{~s} /{ }^{\mathrm{a}}\end{array}$ & 10 & $I / I_{0}$ & $\begin{array}{c}1.2 \times 10^{4} \\
2.25 \times 10^{4} \\
1.7 \times 10^{4} \text { at } 10 \\
\text { ppm }\end{array}$ & [84] \\
\hline $\begin{array}{l}\text { PDI-PY } \\
\text { PDI-PI } \\
\text { PDI-HE } \\
\quad(12)\end{array}$ & n-Alkyl chains & $\begin{array}{l}\mathrm{N} \text {-atom } \\
\text { containing } \\
\text { alkyl and } \\
\text { cycloalkyls }\end{array}$ & Hydrazine & Amperometric & $\begin{array}{c}40 \mathrm{~s} / 10 \mathrm{~s} \\
50 \mathrm{~s} / 10 \mathrm{~s} \\
7 \mathrm{~s} / 7 \mathrm{~s}\end{array}$ & $\begin{array}{l}0.46 \\
0.24 \\
0.17\end{array}$ & $I / I_{O}$ & $\begin{array}{l}2.5 \times 10^{4} \\
1.3 \times 10^{5} \\
1.5 \times 10^{5} \\
\text { at } 10 \mathrm{ppm}\end{array}$ & [85] \\
\hline $\begin{array}{c}\text { PDI-DMB } \\
\text { PDI-TMSA } \\
\text { PDI-TESA } \\
\text { PDI-TPSA } \\
\text { (13) }\end{array}$ & n-Alkyl chains & $\begin{array}{c}\text { C- and } \\
\text { Si-based } \\
\text { acetylenes }\end{array}$ & Hydrazine & Amperometric & $\begin{array}{l}200 \mathrm{~s} /{ }^{\mathrm{a}} \\
200 \mathrm{~s} /{ }^{\mathrm{a}} \\
200 \mathrm{~s} /{ }^{\mathrm{a}} \\
200 \mathrm{~s} /{ }^{\mathrm{a}}\end{array}$ & 10 & $I / I_{0}$ & $\begin{array}{c}2 \times 10^{4} \\
2.1 \times 10^{4} \\
1.7 \times 10^{3} \\
3.9 \times 10^{4} \\
\text { at } 10 \mathrm{ppm}\end{array}$ & [35] \\
\hline $\begin{array}{c}\text { PDI-C } 12 \\
\text { PDI-BR }_{2} C_{12} \\
\text { PDI-CN }_{2} C_{12} \\
(14)\end{array}$ & n-Alkyl chains & $\begin{array}{l}\mathrm{H}, \mathrm{Br} \text {, and } \\
\mathrm{CN}\end{array}$ & Ammonia & Resistive & $\begin{array}{l}50 \mathrm{~s} /{ }^{\mathrm{a}} \\
100 \mathrm{~s} /{ }^{\mathrm{a}} \\
600 \mathrm{~s} /{ }^{\mathrm{a}}\end{array}$ & $1 \%$ & $\Delta R / R_{o} \times 100$ & $\begin{array}{c}40 \% \\
0.075 \% \\
0.75 \text { at } 1 \% \mathrm{NH}_{3}\end{array}$ & [21] \\
\hline $\begin{array}{l}\text { PDI-SOT } \\
\text { PDI-STB } \\
\text { PDI-SPP } \\
(15)\end{array}$ & n-Alkyl chains & $\begin{array}{l}\text { Alkyl- and } \\
\text { phenyl- } \\
\text { based } \\
\text { acetylenes }\end{array}$ & Ammonia & Amperometric & $\begin{array}{l}24 \mathrm{~s} / 12 \mathrm{~s} \\
24 \mathrm{~s} / 10 \mathrm{~s} \\
17 \mathrm{~s} / 6 \mathrm{~s}\end{array}$ & $\begin{array}{l}1.51 \\
0.95 \\
0.48\end{array}$ & $\Delta I \times 100$ & $\begin{array}{c}0.9 \% \\
1.8 \% \\
4.5 \% \\
\text { at } 100 \mathrm{ppm}\end{array}$ & [23] \\
\hline
\end{tabular}


Table 1. Cont.

\begin{tabular}{|c|c|c|c|c|c|c|c|c|c|}
\hline 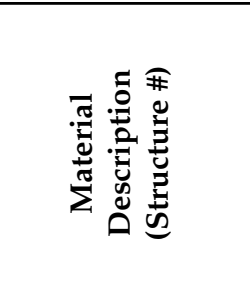 & 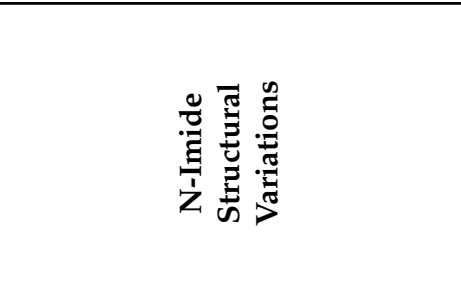 & ن & $\frac{\frac{\pi}{3}}{\frac{\pi}{3}}$ & 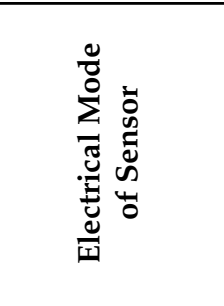 & 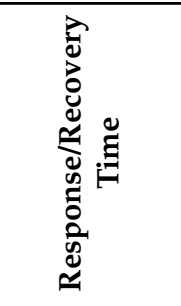 & 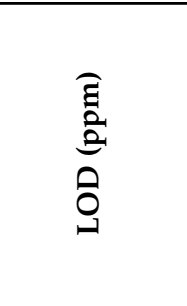 & 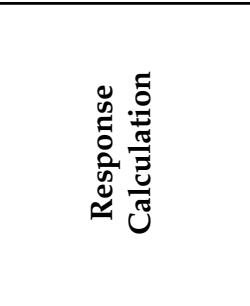 & 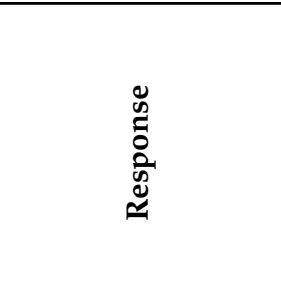 & 岕 \\
\hline $\begin{array}{c}\text { PDI } \\
\text { PDI-N } \\
\text { PDI-2N } \\
(16)\end{array}$ & $\begin{array}{l}\text { n-Alkyl substituents with chiral } \\
\text { center }\end{array}$ & $\mathrm{H}$ and $\mathrm{NO}_{2}$ & Ammonia & Amperometric & $\begin{array}{l}25 \mathrm{~s} / 2 \mathrm{~s} \\
26 \mathrm{~s} / 2 \mathrm{~s} \\
36 \mathrm{~s} / 2 \mathrm{~s}\end{array}$ & $\begin{array}{l}5 \\
3 \\
2\end{array}$ & $\Delta I \times 100$ & $\begin{array}{c}1 \% \\
6.6 \% \\
5.6 \% \\
\text { at } 5 \mathrm{ppm}\end{array}$ & {$[86]$} \\
\hline $\begin{array}{c}\text { PDI } \\
\text { PDI-S } \\
\text { PDI-Se } \\
(17)\end{array}$ & $\begin{array}{l}n \text {-Alkyl substituents with chiral } \\
\text { center }\end{array}$ & $\begin{array}{l}\text { Bridged S } \\
\text { and Se }\end{array}$ & Ammonia & Amperometric & $\begin{array}{l}80 \mathrm{~s} /{ }^{a} \\
80 \mathrm{~s} /{ }^{a} \\
80 \mathrm{~s} /{ }^{\mathrm{a}}\end{array}$ & 100 & $I / I_{0}$ & $\begin{array}{c}250 \\
320 \\
100 \\
\text { at } 100 \mathrm{ppm}\end{array}$ & {$[87]$} \\
\hline $\begin{array}{l}\text { PDI-HIS } \\
\text { (18) }\end{array}$ & $\begin{array}{l}\text { n-Alkyl and histidine } \\
\text { substituents }\end{array}$ & NA & Ammonia & Amperometric & $5 \mathrm{~s} / 20 \mathrm{~s}$ & 0.56 & $\Delta I / I_{0} \times 100$ & $\begin{array}{l}3500 \\
\text { at } 100 \mathrm{ppm}\end{array}$ & {$[24]$} \\
\hline $\begin{array}{l}\text { PDI-MA } \\
\text { (20) }\end{array}$ & $\begin{array}{l}\text { Phenyl substituents containing } \\
\text { amine }\end{array}$ & NA & Nitromethane & Amperometric & $10 \mathrm{~s} / 75 \mathrm{~s}$ & 36,000 ppm & $\Delta I / I_{0}(\%)$ & $65 \%$ at $36,000 \mathrm{ppm}$ & [89] \\
\hline $\begin{array}{l}\text { PDI-MP } \\
\text { (21) }\end{array}$ & $N$-atom containing cycloalkyls & NA & $\begin{array}{l}\text { Hydrogen } \\
\text { peroxide }\end{array}$ & Resistive & $19.5 \mathrm{~s} /{ }^{\mathrm{a}}$ & 0.6 & $\Delta I / I_{o}(\%)$ & $\begin{array}{c}50 \% \\
\text { at } 20 \mathrm{ppm}\end{array}$ & [90] \\
\hline $\begin{array}{c}\text { PDI-PR } \\
\text { PDI-PS } \\
(22)\end{array}$ & $\begin{array}{l}\text { Sulphonic acid complex of } \\
\text { tertiary amine }\end{array}$ & NA & Ethylenediamine & Amperometric & $\begin{array}{c}9 \mathrm{~s} / 7 \mathrm{~s} \\
11 \mathrm{~s} / 14 \mathrm{~s}\end{array}$ & $\begin{array}{l}1.07 \\
0.86\end{array}$ & $\Delta I \times 100$ & $\begin{array}{c}1.5 \% \\
17 \% \\
\text { at } 100 \mathrm{ppm}\end{array}$ & [91] \\
\hline $\begin{array}{l}\text { PDI-TC } \\
(23)\end{array}$ & $\begin{array}{l}\text { n-Alkyl and -OH substituted } \\
\text { alkyl chains }\end{array}$ & $\mathrm{Cl}$ & Trimethyl-amine & Amperometric & $325 \mathrm{~s} / 510 \mathrm{~s}$ & 0.2 & $\left(I-I_{0}\right) / I_{O} \times 100$ & $\begin{array}{c}18 \% \\
\text { at } 10 \mathrm{ppm}\end{array}$ & [92] \\
\hline $\begin{array}{l}\text { PDI-PB } \\
\text { (24) }\end{array}$ & n-Ethylhexyl & $\begin{array}{l}\text { Br and Aza- } \\
\text { cyclobutane }\end{array}$ & Pyridine & Resistive & $1 \mathrm{~s} /{ }^{\mathrm{a}}$ & $375 \mathrm{pbb}$ & $\Delta R / R_{o} \times 100$ & $2200 \%$ at $375 \mathrm{ppm}$ & [93] \\
\hline
\end{tabular}

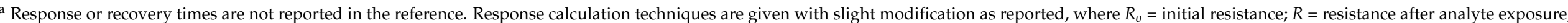

$\Delta R=$ change in resistance; $I_{0}=$ initial current; $I=$ current after analyte exposure; and $\Delta I=$ change in current. 
Sensitivity is the minimum fractional variation in the output signal $\left(\Delta I / I_{o}\right.$ and $\left.\Delta R / R_{o}\right)$ of a sensor upon exposure to an analyte, where $I_{o}$ and $R_{o}$ are the current and resistance, before exposure to the target gas respectively, and $\Delta I$ and $\Delta R$ are the change in the current and resistance, respectively, when the sensor is exposed to a certain quantity of target analyte. Selectivity is one of the most significant sensing parameters because there are a variety of interfering gases that are detrimental to accurate target analyte detection. Selectivity is the capability of a sensor to recognize a specific target gas among a mixture of gases. Selectivity is generally examined by comparing the cross-sensitivity towards several analytes at a particular concentration. Stability is another critical factor that is defined as the capability of a sensor to repeat the same results for a target gas for a fixed period of time. Hysteresis is a variance of the sensor output at a specified point of the input signal when it is approached from the opposite direction. Low levels of hysteresis are desirable. Response and recovery times are measured to quantify the sensing speed of a sensor. Generally, the response time is defined as the time taken for the current/resistance to change from the baseline current/resistance $\left(I_{o} / R_{o}\right)$ to $90 \%$ of the maximum change in current/resistance at a specific level of the target analyte. On the other hand, the recovery time is defined as the time taken by a sensor to reach the baseline state after completely removing the target analyte. The LOD is the lowest analyte concentration that a sensor can sense or detect reliably. The LOD is generally defined based on signal to noise ratio $(\mathrm{S} / \mathrm{N})$ and is typically determined by an $\mathrm{S} / \mathrm{N}$ of 3:1. The working temperature is the temperature at which a sensor can work effectively with high sensitivity and stability. Table 1 aims to summarize many of the reported PDI based gas sensors of merit and their overall performance.

\section{Hydrazine Sensing}

Hydrazine is a hygroscopic gas that is widely used in pharmaceutical industries, rocket propulsion systems, and photographic chemicals [94]. Though hydrazine is an important industrial material that is used as a hydrogen source, it is also generally known as a hepatotoxic neurotoxin, a carcinogen, and very harmful to human health [95]. As a result and through oral or dermal contact, consumption, or inhalation, hydrazine primarily affects the central nervous system, liver, lungs, and kidneys of living organisms. Additionally, it can seriously affect the reproductive system of living organisms. The minimum permissible limit of hydrazine in the environment is ten parts per billion (ppb), recommended by the United States Environmental Protection Agency (USEPA) [96]. Therefore, the realization of reliable gas sensors for hydrazine is essential for those industries using commercial quantities. Most PDI-based hydrazine sensors have been developed in resistive and amperometric configurations, and their sensing parameters are summarized in Table 1.

In 2009, Huang et al. [48] prepared self-assembled one-dimensional (1D) nanotubes and nanorods containing PDI-I (structure 1; Figure 10) by evaporating an aqueous solution of PDI-I and employed them in resistive sensors. Different morphologies, including nanotubes with a diameter of 100-300 $\mathrm{nm}$ and nanorods with a diameter of $200-300 \mathrm{~nm}$ (Figure $3 \mathrm{a}, \mathrm{b}$ ), were achieved using a variety of solvents and preparations. The self-assembled nanotubes and nanorods showed high sensitivities (100 and $1000\left(R / R_{o}\right)$, respectively) towards $10 \mathrm{ppm}$ of hydrazine and phenylhydrazine vapor with moderate responses (50 and 100, respectively) to $10 \mathrm{ppm}$ of triethylamine vapors. The resistance of PDI-I nanotubes and nanorods was recorded using a four-probe technique. A decrease in the resistance of the nanotubes and nanorods was noted upon exposure to hydrazine vapors (10 ppm), which was due to the presence of long-range $\pi$-electron delocalization via the surface doping of hydrazine. The change in the resistance of the nanorods was modest compared to the nanotubes (Figure 3c), though both demonstrated good response times (180 and $102 \mathrm{~s}$, respectively) towards hydrazine.

The same research group also synthesized symmetrical sugar-based PDI derivative PDI-BAG (structure 2; Figure 10) and studied the effect of various solvents on the morphology of PDI-BAG [56]. Their study revealed that PDI-BAG has a good solubility in $\mathrm{N}, \mathrm{N}$-dimethylformamide (DMF) and that self-assembled nanoribbons and nanofibers of 
PDI-BAG were formed in different ratios of water and DMF (Figure $4 a, b$ ). Sensors based on the nanoribbon structure displayed a better sensing performance towards hydrazine vapor when compared with nanofiber bundles. The nanoribbons showed a higher sensitivity $\left(10^{4} R_{o} / R_{S}\right)$ than the nanofiber bundles $\left(10^{2} R_{o} / R_{S}\right)$, as shown in Figure $4 \mathrm{c}$, due to better organization of the PDI-BAG molecules. The better sensitivity of the nanoribbons towards hydrazine appeared to be at the expense of a slower response (400 s). Furthermore, the prepared chiral nanoribbons showed higher sensitivity than the achiral nanostructures, which was due to high crystallinity and single handed chirality [48]. Further studies on a series of sugar-based PDIs-OBAG, DBAG, and HBAG (structure 3; Figure 10)-bearing various achiral alkyl chains to modulate hydrophilic and hydrophobic interactions to adjust the supramolecular helicity by varying alkyl chain length as a way to explore the design principles to optimal results was also reported [80]. The helical nanostructures of all the three molecules were obtained from tetrahydrofuran (THF) $/ \mathrm{H}_{2} \mathrm{O}$. The responses of OBAG-, DBAG-, and HBAG-based sensors were recorded as a function of change in current towards hydrazine vapor. The DBAG-based sensor displayed the highest sensitivity $\left(5.2 \times 10^{4} \mathrm{I} / \mathrm{I}_{0}\right)$ when compared with OBAG and HBAG $\left(2.5 \times 10^{4}\right.$ and $4 \times 10^{4} \mathrm{I} / \mathrm{I}_{0}$, respectively) (Figure $4 \mathrm{~d})$, mainly due to the smaller rotation angle $\left(28^{\circ}\right.$ or $\left.-30^{\circ}\right)$ between adjacent PDI molecules in comparison to those of OBAG $\left(32^{\circ}\right.$ or $\left.-32^{\circ}\right)$ and HBAG $\left(30^{\circ}\right.$ or $\left.-31^{\circ}\right)$. The smaller rotation angle for DBAG indicates that a larger $\pi-\pi$ overlap of the adjacent perylene core is expected to increase mobility and lead to maximum current (five orders of magnitude different). All the sensors displayed a comparatively high sensitivity $\left(10^{4} I / I_{o}\right)$ and quick response (350 s) than the previously reported sugar-based PDI derivatives [56], though there was no investigation regarding selectivity, recovery, and reproducibility to allow for a further comparison.
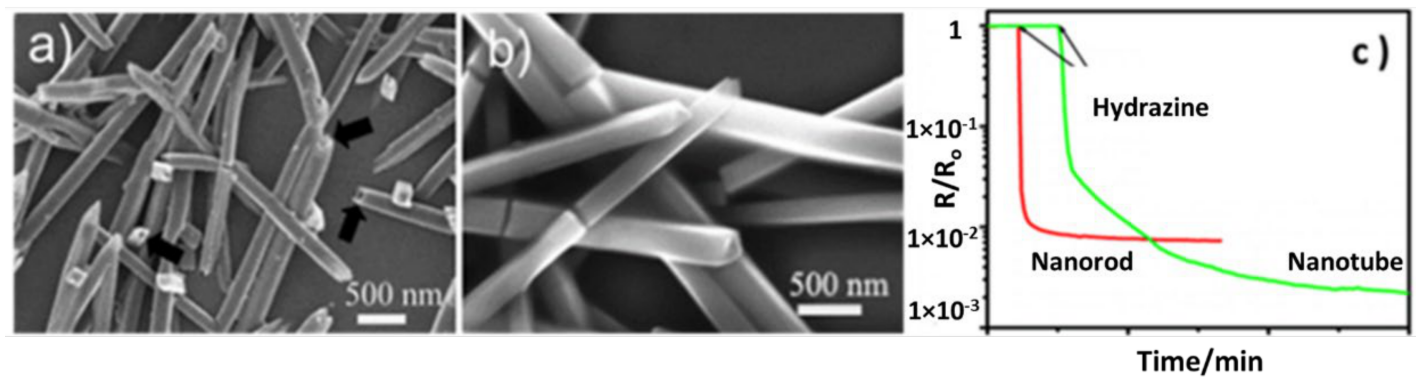

Figure 3. SEM images of (a) nanotubes and (b) nanorods of PDI-I. (c) Resistance modulation $\left(R / R_{o}\right)$ vs. time $(t)$ curve measured on a single nanotube and nanorod hydrazine vapor. Adapted with permission [48].

The effect of different electron-donor and electron-withdrawing functional groups on the sensing performance of PDIs was also ben investigated [22]. Two core-substituted, tetrachlorinated PDI derivatives, $\mathrm{PDI}-\mathrm{ClC}_{12}$ and $\mathrm{PDI}-\mathrm{ClC}_{4} \mathrm{~F}_{7}$, bearing electron-donor dodecyl and electron-withdrawing perfluorobutyl groups at the imide positions, as well as one core-unsubstituted PDI-C 12 (structure 4; Figure 10), were synthesized for hydrazine vapor sensing. Interestingly for the design and development of suitable sensors using PDIs, the resistance of both the core-substituted PDIs sensors decreased sharply $\left(10^{4} \mathrm{R} / \mathrm{R}_{o}\right)$ upon exposure to hydrazine vapor $(10 \mathrm{ppm})$ when compared to the core-unsubstituted PDI- $\mathrm{C}_{12}$ $\left(100 R / R_{o}\right)$. The sensing performance of these PDIs was shown to be independent of their morphologies and surface areas but very much aligned to the difference in reduction potentials, caused by different core-substituted groups, indicating the electronics dominate structure. For example, PDI-ClC 12 and $\mathrm{PDI}-\mathrm{ClC}_{4} \mathrm{~F}_{7}$ presented similar sensing results $\left(10^{4}\right.$ at $\left.10 \mathrm{ppm}\right)$ due to similar LUMO energy levels $(-4.22$ and $-4.28 \mathrm{eV}$, respectively). It was also reported that different imide substituents have a secondary effect on the sensing performance. The results showed that PDI derivatives with lower reduction potentials enable a highly sufficient charge exchange and eventually lead to high gas sensitivity. PDI$\mathrm{ClC}_{12}$ - and $\mathrm{PDI}-\mathrm{ClC}_{4} \mathrm{~F}_{7}$-based sensors showed slow response (600 s), and no investigation 
on recovery time and repeatability was reported. The good selectivity of these PDI sensors towards hydrazine vapor was quantified when compared with carbon monoxide, hydrogen sulphide, and hydrogen vapor.
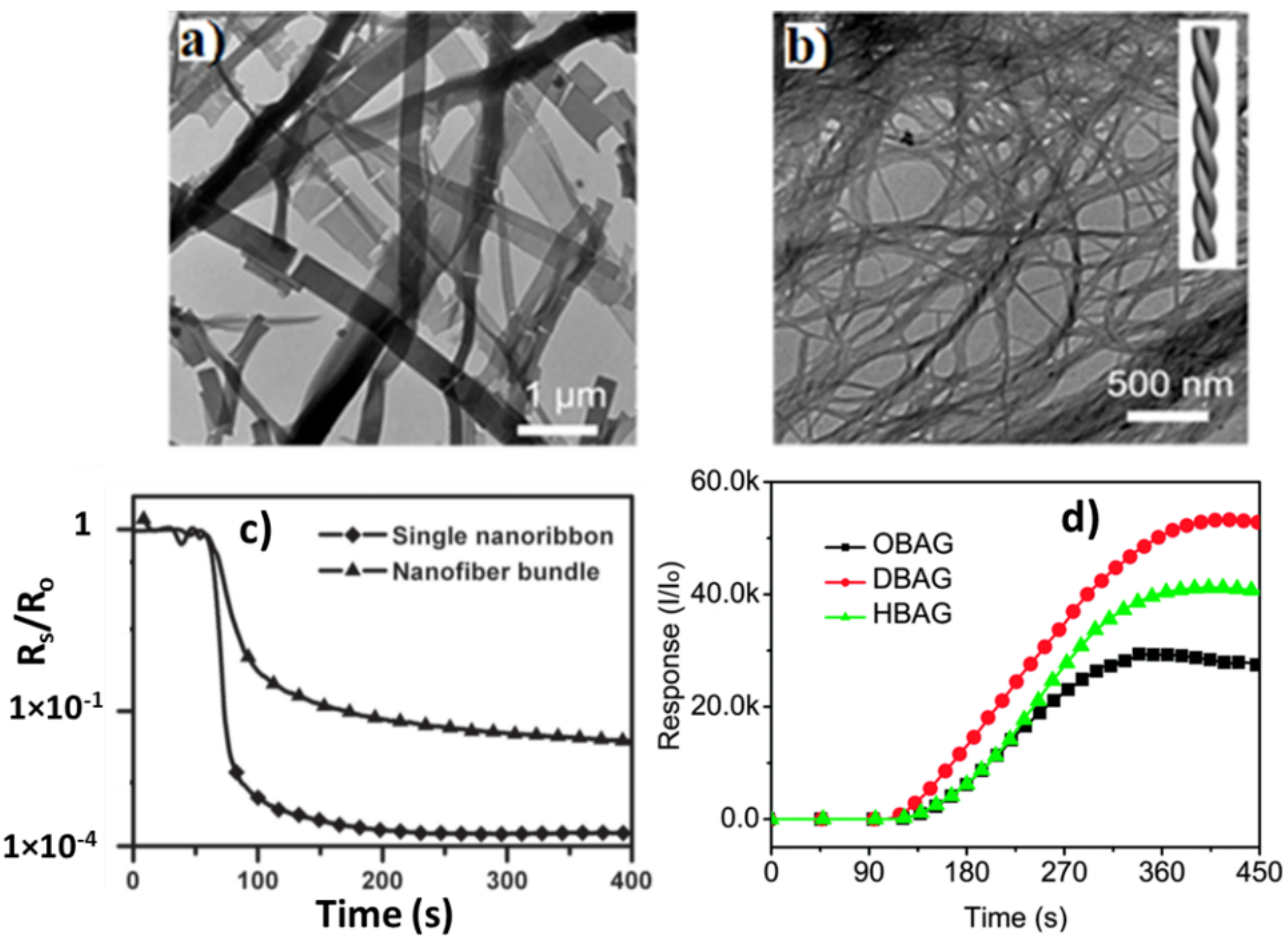

Figure 4. TEM images of PDI-BAG (a) nanoribbons and (b) nanofiber obtained from $\mathrm{H}_{2} \mathrm{O} / \mathrm{DMF}(\mathrm{N}, \mathrm{N}$ dimethylformamide) mixed solvents with different volume ratios of 20/80 and 60/40, respectively. (c) Sensing responses of single nanoribbon and nanofiber bundles after the injection of hydrazine vapor. (d) Sensing responses of OBAG, DBAG, and HBAG devices obtained from THF $/ \mathrm{H}_{2} \mathrm{O}(20 / 80 v / v)$ in hydrazine vapor. Adapted with permission $[56,80]$.

Wang et al. [81] also investigated the relationship between the reduction potential of PDI derivatives and its sensing properties towards hydrazine vapor and also studied the effect of different humidity levels, operating temperatures, and film thickness on the sensing performance of the sensor. They synthesized a twisted PDI derivative (PDI-d) (structure 5; Figure 10) exhibiting a low reduction potential. The PDI-d device was continuously exposed to hydrazine vapor of different concentrations while recording the real-time resistance. Prior to the exposure to hydrazine vapor, the resistance in air was noted as $0.75 \mathrm{G} \Omega$, which was significantly decreased to $0.42 \mathrm{G} \Omega$ after the exposure to 5 ppm of hydrazine vapor. When the hydrazine vapor was removed, the resistance returned to its initial value within $3 \mathrm{~s}$, which indicated that the PDI-d-based sensor had a fast response and continued cycles showed a high reproducibility. Difficulties arose at a high concentration $(800 \mathrm{ppm})$ of hydrazine, which led to instability in the device, which was attributed to the variation in the film morphology demonstrated by SEM images before and after exposure to 800 ppm of hydrazine vapor (Figure 5a,b). The effect of relative humidity levels, temperatures, and film thickness on the sensing performance of the PDI-d film device was investigated in these examples, in detail. The response of the device towards hydrazine vapor slightly improved (within 10\%) with the increase of the relative humidity (Figure 5c). It is believed that a higher humidity is conducive for the hydrolyzation of hydrazine or, in fact, the reduction in the nucleophilicity of hydrazine. The response of the sensor was almost the same at the temperature range of $0-60{ }^{\circ} \mathrm{C}$ (Figure $5 \mathrm{~d}$ ). To study the effect of film thickness on the sensing performance, volumes of 20 and $50 \mu \mathrm{L}$ of PDI-d in dichloromethane were drop-casted on IDEs. The thick film showed an enhanced sensitivity and a slow response/recovery, which can be attributed to the greater amount of PDI-d rad- 
ical anions produced on the thicker film, therefore requiring a longer time for the transition between PDI-d and PDI- $\mathrm{d}^{-}$. Additionally, a comparison between the sensing performance of unsubstituted-PDI with higher reduction potential and PDI-d confirmed that reduction potential plays a critical role in the sensing performance of PDI-based sensors.
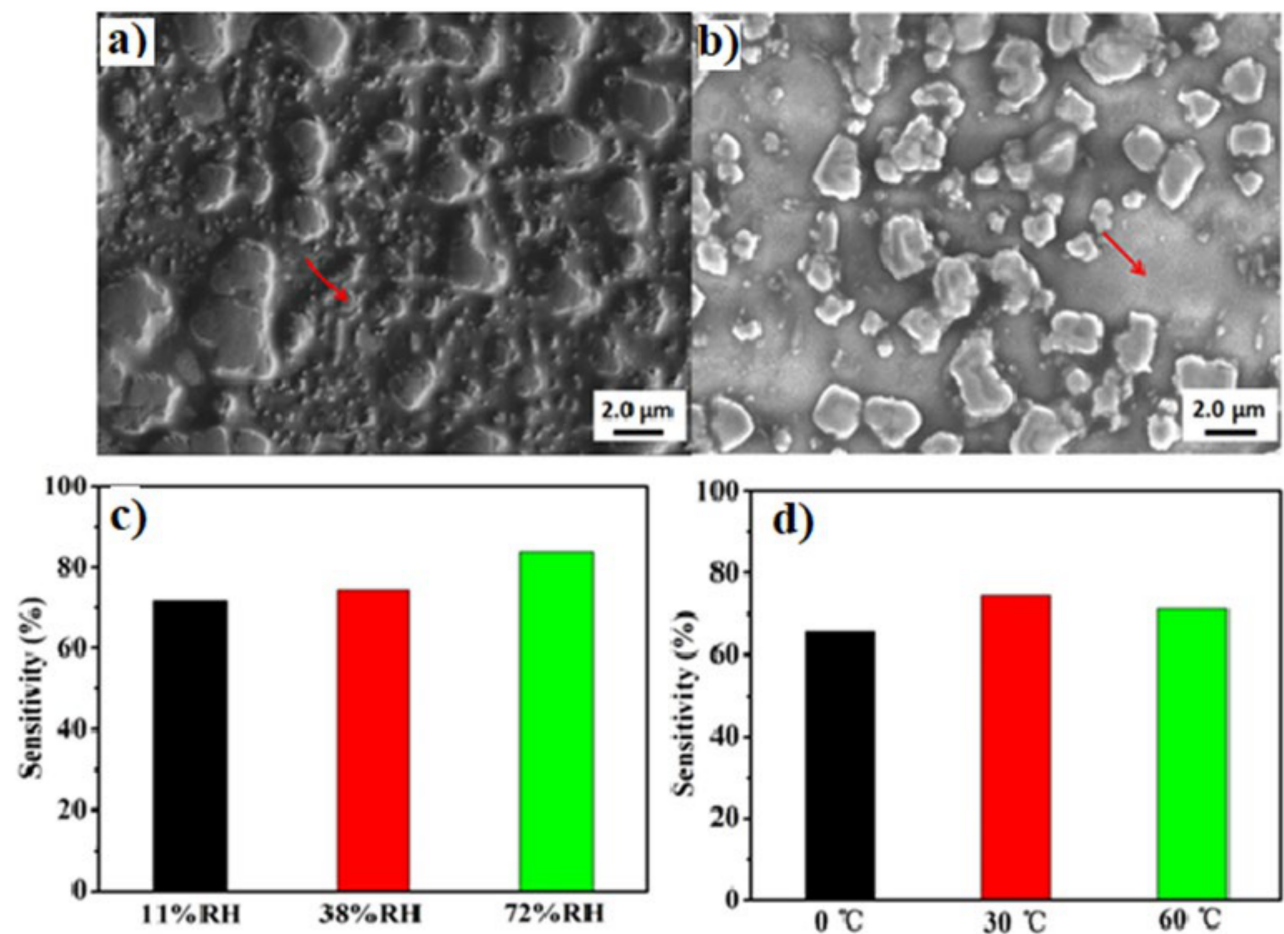

Figure 5. SEM images of a PDI-d film (a) before and (b) after treatment with 800 ppm of hydrazine vapor for $20 \mathrm{~h}$. Red arrows indicates micro/nano particles that disappear after exposure to the target gas, indicating that the surface of the film is affected by the target gas. The effect of (c) relative humidity and (d) temperature on the sensing properties of a PDI-d film device. Adapted with permission [81].

The effect of core-substituted groups on the sensing properties of PDI is critical to our understanding of the tolerance and enhanced capability based on the ease of functionalization of organic compounds [82]. By way of example, three different derivatives of $\mathrm{PDI}-\mathrm{PDI}-\mathrm{C}_{10}, \mathrm{PDI}-\mathrm{Br}_{2} \mathrm{C}_{10}$, and PDI- $\mathrm{BP}_{2} \mathrm{C}_{10}$ (structure 6; Figure 10)-were synthesized in order to study the effect of bay-substituted groups on their gas-sensing performance. It was reported that the sensitivity towards $10 \mathrm{ppm}$ of hydrazine vapor was higher for the core-phenoxy-substituted PDI-BP $\mathrm{C}_{10}\left(10^{4} \mathrm{I} / \mathrm{I}_{0}\right)$ and lower for the core-brominated PDI$\mathrm{Br}_{2} \mathrm{C}_{10}\left(10^{2} I / I_{0}\right)$ when compared with the sensing performance of the core-unsubstituted PDI-C $10\left(10^{3} I / I_{0}\right)$. The different responses to hydrazine for $P D I-B_{2} C_{10}$ and PDI-C 10 gas sensors were again proposed to be less reliant on their morphologies and surface areas, and they were attributed to the twisted skeleton of $\mathrm{PDI}-\mathrm{Br}_{2} \mathrm{C}_{10}$ that derived from non-bonded repulsions between the bromine atoms that resided in the core-area. However, a lower activation energy level and a higher delocalized system efficiently made up for deficiencies in carrier transport that originated from the distorted packing of perylene units and led to only one order of magnitude in current increase for PDI- $\mathrm{BP}_{2} \mathrm{C}_{10}$ when compared with PDI- $\mathrm{C}_{10}$. The sensor using the PDI- $\mathrm{BP}_{2} \mathrm{C}_{10}$ active layer showed a low LOD $(0.75 \mathrm{ppm})$, good sensitivity $\left(10^{4}\right)$, and better response and recovery times (450 s/150 s) compared with previously reported PDI-ClC 12 - and PDI-ClC $\mathrm{F}_{7}$-based sensors [22]. From these results, it can be postulated that sensing performance is less dependent on the morphologies and surface area of the sensors. Furthermore, these sensors were extremely selective towards hydrazine vapor when compared with carbon monoxide, hydrogen, nitrogen dioxide, and 
ozone vapor. These results demonstrated that bay-substituted groups have a significant influence on the sensitivity and stability of PDI-sensing devices.

The Huang group further investigated the effect of core-substituted aromatic groups on the sensing performance of PDIs [58]. For that purpose, they synthesized four different core-substituted aromatic PDI derivatives-DEY, DSPY, DTPY, and DFPY (structure 7; Figure 10) - to explore improved hydrazine sensing. The experimental results revealed that current increased five times towards $10 \mathrm{ppm}$ of hydrazine for PDI-DEY compared to the PDI-DSPY -, PDI-DFPY-, and PDI-DPTY-based sensors. The results reconfirmed that sensor performance was not dependent on the morphologies and surface areas of the materials. The high sensitivity $\left(10^{5} \mathrm{I} / I_{0}\right)$ of the PDI-DEY-based sensor was attributed to a lower LUMO energy level $(-3.68 \mathrm{eV})$ and activation energy with a smaller interplanar spacing. The aromatic groups at the bay positions appeared to have a prominent effect on the PDI-sensing performance by modulating the energy level, stacking modes, and interplanar spacing. Though the sensors showed an enhanced sensitivity $\left(10^{4}-10^{5} I / I_{0}\right)$, they did present a slower response rate $(800 \mathrm{~s})$ and a higher LOD (10 ppm) than the PDI-ClC $12^{-}$and PDI$\mathrm{BP}_{2} \mathrm{C}_{10}$-based sensors, and there was no investigation into the recovery, repeatability, and selectivity of the prepared sensors. Taking this further, the team investigated the effect of electron-withdrawing groups on the hydrazine-sensing performance of PDI-based sensors to complement the earlier work on electron-donating groups within PDI- $\mathrm{BP}_{2} \mathrm{C}_{10}$. Two PDI derivatives, namely PDI-CNC 10 and PDI-ClC 10 (structure 8; Figure 10), differentiated by electron-withdrawing groups, were synthesized and formed regular and smooth $1 \mathrm{D}$ micro/nanorods (Figure 6a,b) from a chloroform/methanol solution [34]. The sensing studies undertaken in comparison revealed that $\mathrm{PDI}-\mathrm{ClC}_{10}$ was more sensitive $\left(10^{4} I / I_{0}\right)$ than PDI-CNC $10\left(10^{3} I / I_{0}\right)$, but the PDI-CNC 10 derivative exhibited a better stability in an open environment due to its low lying LUMO level $(-4.36 \mathrm{eV})$ and highly crystalline structure. Both the PDI-ClC 10 and PDI-CNC 10 devices showed low LOD (at 1 and 2 ppm, respectively) and a better response time (350 s) than the PDI-ClC $\mathrm{C}_{4} \mathrm{~F}_{7}$-based sensor. The repeatability and reproducibility (Figure $6 \mathrm{c}, \mathrm{d}$ ) of both sensors were found to be excellent, and the sensor showed the highest selectivity towards hydrazine in presence of carbon monoxide and ammonia. The results revealed that core-substituted electron-withdrawing groups have a substantial and positive effect on the sensitivity and stability of PDI-based gas-sensing devices for future design consideration.

In a complementary work, Liu et al. [50] also investigated the effect of core-substituted groups on the sensing performance of PDI-based sensors against hydrazine through PDIpyrimidine and PDI-ph (structure 9; Figure 10). The PDI-pyrimidine-sensor displayed a high sensitivity (56\%), significant reproducibility, excellent selectivity, and better longterm stability towards hydrazine vapor. The response and recovery times of the sensor towards $10 \mathrm{ppm}$ of hydrazine vapor were calculated to be as low as 0.7 and $0.8 \mathrm{~s}$, respectively. From cyclic voltammetry and absorption studies, it was confirmed that the redox potential of PDI played an important role in the sensing performance. The effect of humidity and temperature was also investigated. The sensors showed a high sensitivity at high humidity levels from $70 \%$ to $96 \%$ but a slower response/recovery (Figure 7a), which was most likely due to the solvation of hydrazine by the water. While the sensor showed stability through a consistent response for an operating temperature range of $20-60{ }^{\circ} \mathrm{C}$, elevated temperatures $\left(>70^{\circ} \mathrm{C}\right)$ caused a significant reduction in the sensitivity (Figure $7 \mathrm{~b})$. It is believed that at a high temperature $\left(70^{\circ} \mathrm{C}\right)$, the interaction between hydrazine vapor and pyrimidine-PDIs is reduced because the adsorption is exothermic. As a result, the sensitivity of the sensor is decreased. The effect of film thickness was also investigated in this study. For that purpose, three sensors with different thicknesses $(8,14$, and $25 \mu \mathrm{m}$ ) were prepared, among which the thicker sensors showed higher sensitivities $(\sim 88.5 \%)$ but concomitant slower response and recovery times (5.3 $\mathrm{s}$ and $8.2 \mathrm{~s}$, respectively) in comparison (Figure 7c). Sensitivity studies indicated this sensor showed the highest selectivity for hydrazine when compared to other reductive vapors such as ammonia, t-butylamine, $n$-butylamine, diethylamine, triethylamine, and aniline (Figure $7 \mathrm{~d}$ ). The 
enhanced performance of pyrimidine-PDI-based sensors yielding better sensitivity, selectivity, long-term stability, and short response/recovery times than the previously reported PDI-based sensors was an important advance in the design of organic sensors.
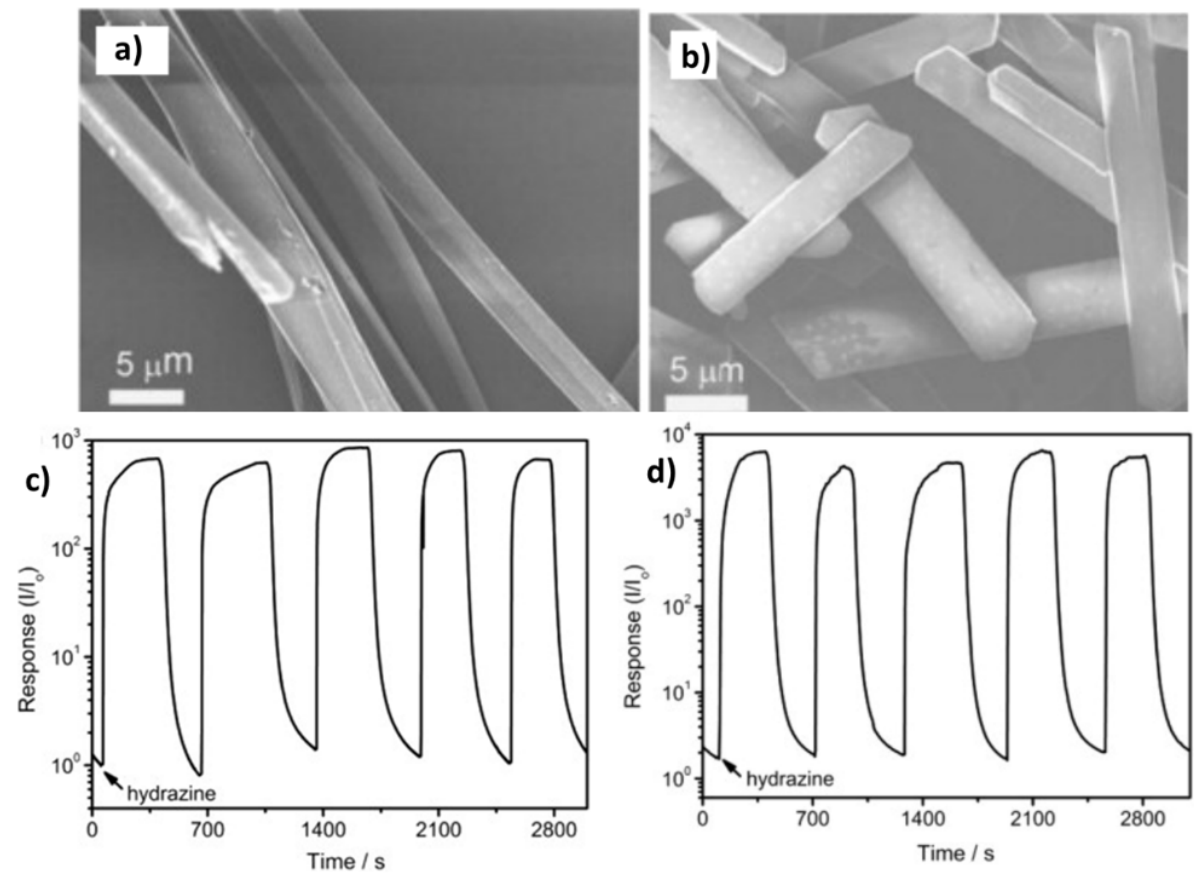

Figure 6. SEM images of (a) PDI-CNC 10 and (b) PDI-ClC 10 illustrating the similarity in a nanorod structure. Dynamic responses of (c) PDI-CNC 10 and (d) PDI-ClC 10 gas sensors towards 8 ppm of hydrazine vapor show the sensitivity increase of the latter based on the response value. Adapted with permission [34].
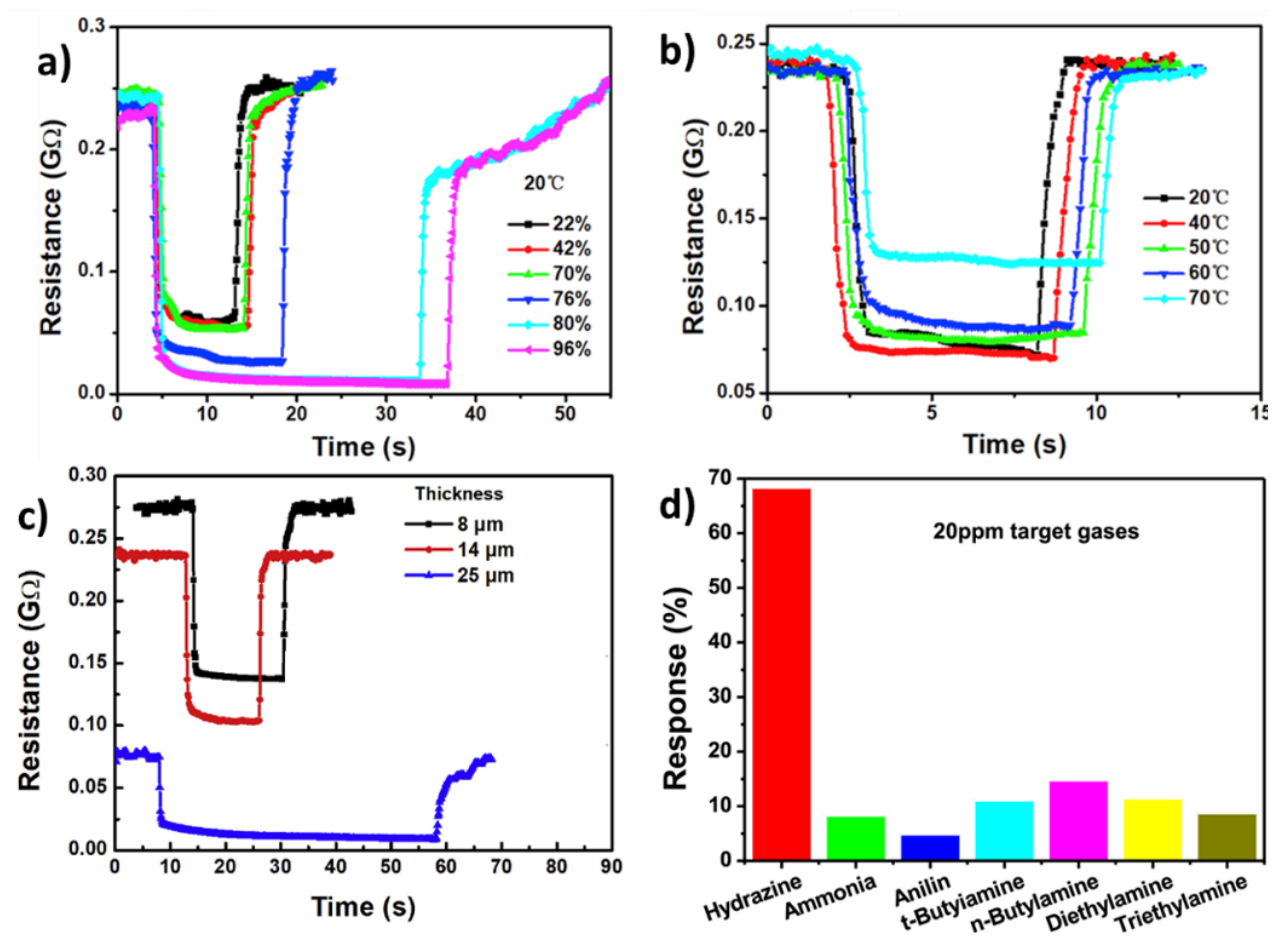

Figure 7. The effect of (a) relative humidity, (b) operating temperature, and (c) film thickness on the sensing properties of a PDI-pyrimidine sensor. (d) The response of a PDI-pyrimidine sensor towards different analytes (20 ppm). Adapted with permission [50]. 
With the advent of positive effects of core-substitution on the performance of PDI sensors through torsion strain, added steric effects, which also change the molecular ability to stack effectively, were evaluated in a simple series $\mathrm{PH}, \mathrm{TPH}$, and $\mathrm{OPH}$ (structure 10; Figure 10), in which the 4-alkylaryl groups differed from $\mathrm{H}$ to $t$-butyl to $t$-octyl, respectively [83]. With reference to hydrazine vapor sensing, among these PDI derivatives, OPH displayed the highest response $\left(1800 \mathrm{I} / \mathrm{I}_{0}\right.$ at $\left.10 \mathrm{ppm}\right)$ (Figure $8 \mathrm{~d}$ ) due to its smallest torsion angle $\left(25.80^{\circ}\right)$, better crystalline structure Figure $\left.8 \mathrm{c}\right)$, and smallest activation energy $(1.03 \mathrm{eV})$ within a face-to-face stacking mode. An ordered crystalline structure (Figure $8 \mathrm{~b}$ ) with a smaller interplanar spacing and modest activation energy $(1.04 \mathrm{eV})$ contributed to the average performance $\left(520 \mathrm{I} / \mathrm{I}_{0}\right)$ of TPH. In contrast, the largest activation energy $(1.05 \mathrm{eV})$ and torsion angle $\left(26.14^{\circ}\right)$ with a meager crystalline structure (Figure 8a) caused $\mathrm{PH}$ to be the least-efficient sensor $\left(130 \mathrm{I} / I_{0}\right)$. All three sensors, $\mathrm{PH}, \mathrm{TPH}$ and $\mathrm{OPH}$, displayed low LOD values $(0.6,0.5$, and $0.5 \mathrm{ppm}$, respectively) and quick response and recovery times $(116 / 19,163 / 52$, and $170 \mathrm{~s} / 58 \mathrm{~s}$, respectively) in comparison with previously reported PDI-based sensors. This study provides useful information on new factors such as torsion angle, morphology, and activation energy that could lead to the enhanced sensing performance of PDI-based sensors that are remote from the electronic function of the active material. To investigate the improved sensing performance of PDIs by further modulating the intermolecular interactions of PDI molecules, a series of stereochemically defined PDI derivatives-OT, ROT, and SOT (structure 11; Figure 10)—bearing pairs of racemic and $R$ - and $S$-chiral hydroxyalkyl chains were synthesized [84]. While sensing gases should not rely on a chiral auxiliary, either as enantiomers or diastereomers, because most gases are achiral species, the hydrazine-sensing responses of PDI-OT, PDI-ROT, and PDI-SOT devices were recorded using a two-probe technique. Upon exposure to $10 \mathrm{ppm}$ of hydrazine vapor, it was found that, surprisingly, the increase in the current for PDI-ROT was approximately 1.5 times that for its enantiomer PDI-SOT and twice that of the racemic mix of diastereomers PDI-OT (Figure 9d). All three sensors showed a response time of approximately $350 \mathrm{~s}$, and there was no investigation about the recovery, repeatability, and selectivity. The difference in enantiomeric activity for PDI-ROT was rationalized by two factors: (a) a smaller torsional angle of 15.55 and, importantly, (b) the generation of a continuous and uniform film surface (Figure 9b). Furthermore, the PDI-ROT sensor exhibited an improved sensitivity than the PH, TPH, and OPH sensors, and this indeed may be attributable to a small torsional angle or additional conjugation. The slower response and higher LOD is more likely to be attributed to a poorer surface morphology than the $\mathrm{PH}, \mathrm{TPH}$, and OPH sensors. The results suggest that the sensitivity of these devices is independent on film thickness, as shown in Figure 9e.

The sensitivity of PDI-based sensors can also be improved by incorporating electrondonating substituents into the core locations of PDI [85]. Three PDI derivatives-PDI-PY, PDI-PI, and PDI-HE (structure 12; Figure 10)—ere synthesized with piperidinyl, pyrrolidinyl, and $n$-hexylamino groups at the bay 1,7-positions of the perylene skeleton, respectively. Experimental results revealed that the hexylamino-based sensor performed best, generating quick response and recovery times (both $7 \mathrm{~s}$, respectively), a low LOD $(0.17 \mathrm{ppm})$, and the highest response $\left(1.5 \times 10^{5} \mathrm{I} / \mathrm{I}_{0}\right)$. This performance was again attributed to its higher electron density as a result of the EDG, the smallest torsional angle $\left(16.83^{\circ}\right)$, and a crystalline structure affording a tighter $\pi-\pi$ distance of $3.55 \AA$. PDI-PY sensors bearing a piperidinyl group afforded inferior sensing results $\left(1.5 \times 10^{4} I / I_{0}\right)$ because of its poor crystalline structure, weaker $\pi-\pi$ orbital overlap, and resulting higher interplanar spacing of $3.62 \AA$ as a result of packing the piperidyl groups. Selectivity towards hydrazine over ammonia and other volatile gases was displayed. 

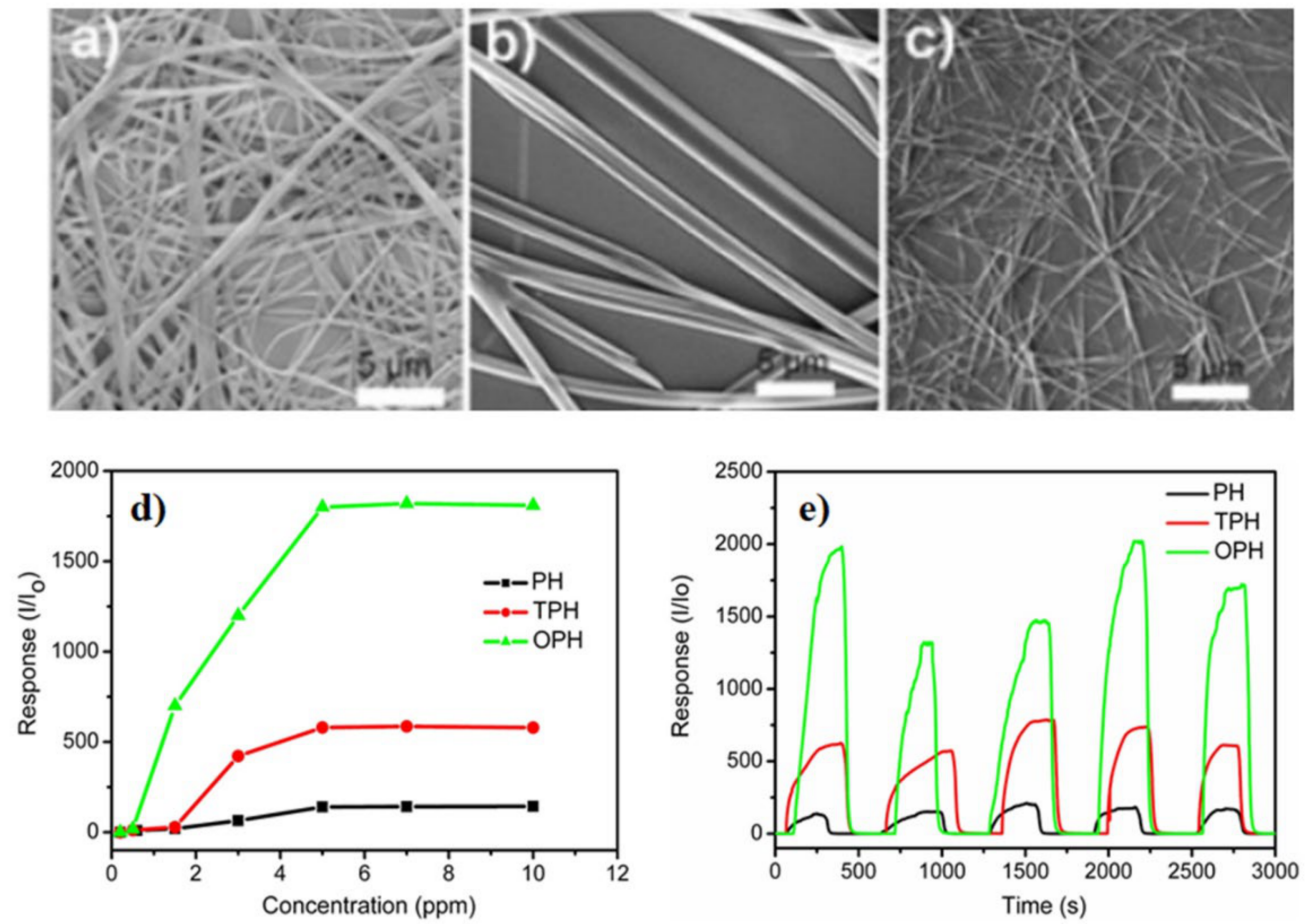

Figure 8. SEM images of microstructures of the (a) PH, (b) TPH, and (c) OPH PDIs. (d) The response modulation-concentration curves show an enhancement in $\mathrm{OPH}$ and (e) the dynamic responses of the $\mathrm{PH}, \mathrm{TPH}$, and $\mathrm{OPH}$ devices in hydrazine vapor (5 ppm). Adapted with permission [83].
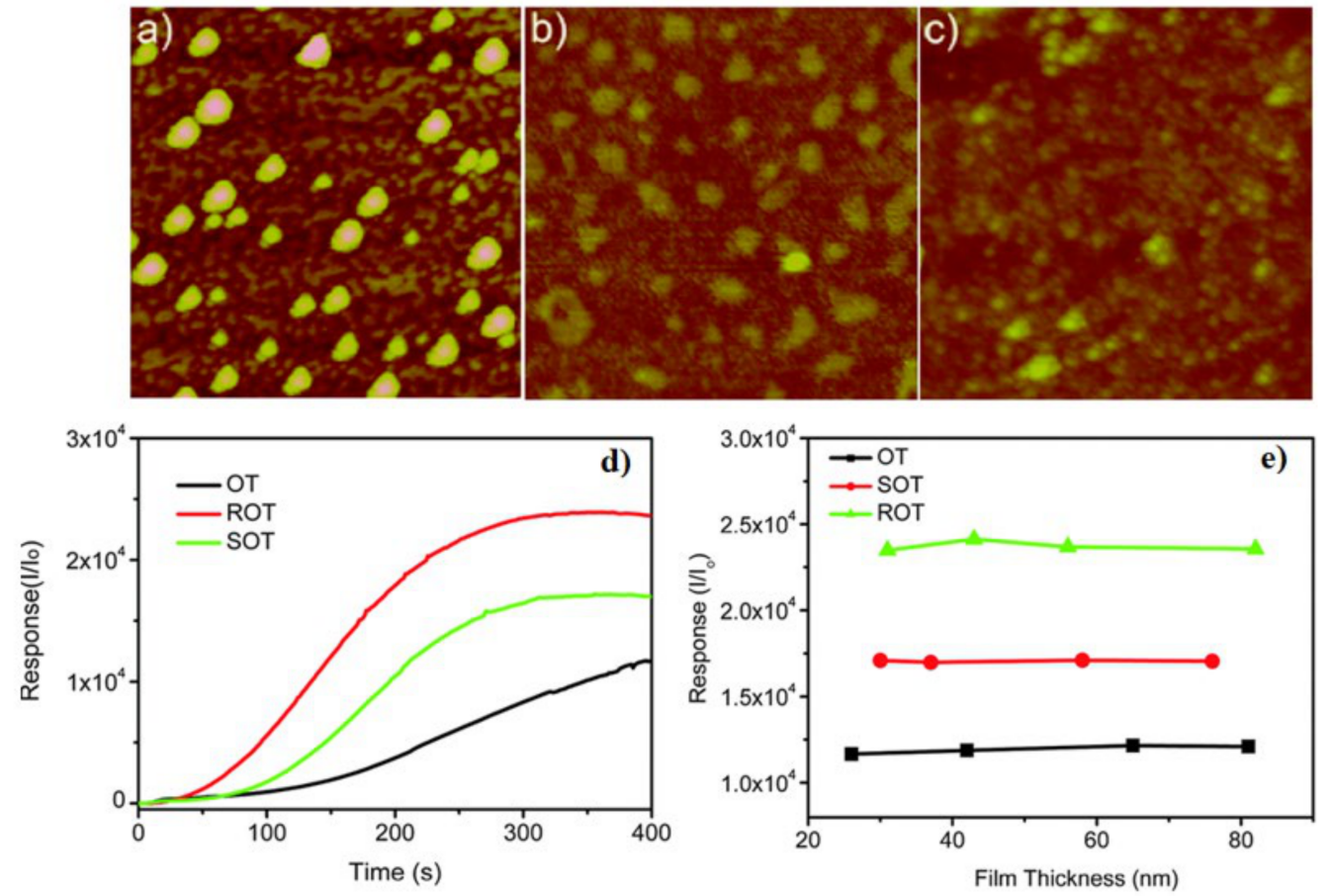

Figure 9. AFM images of thin films $(2 \times 2 \mu \mathrm{m})$ of (a) OT, (b) ROT, and (c) SOT devices. (d) Current modulation $\left(I / I_{o}\right)$-time $(t)$ and $(\mathbf{e})$ response modulation-film thickness curves of OT, ROT, and SOT devices in saturated hydrazine vapor (10 ppm). Adapted with permission [84]. 

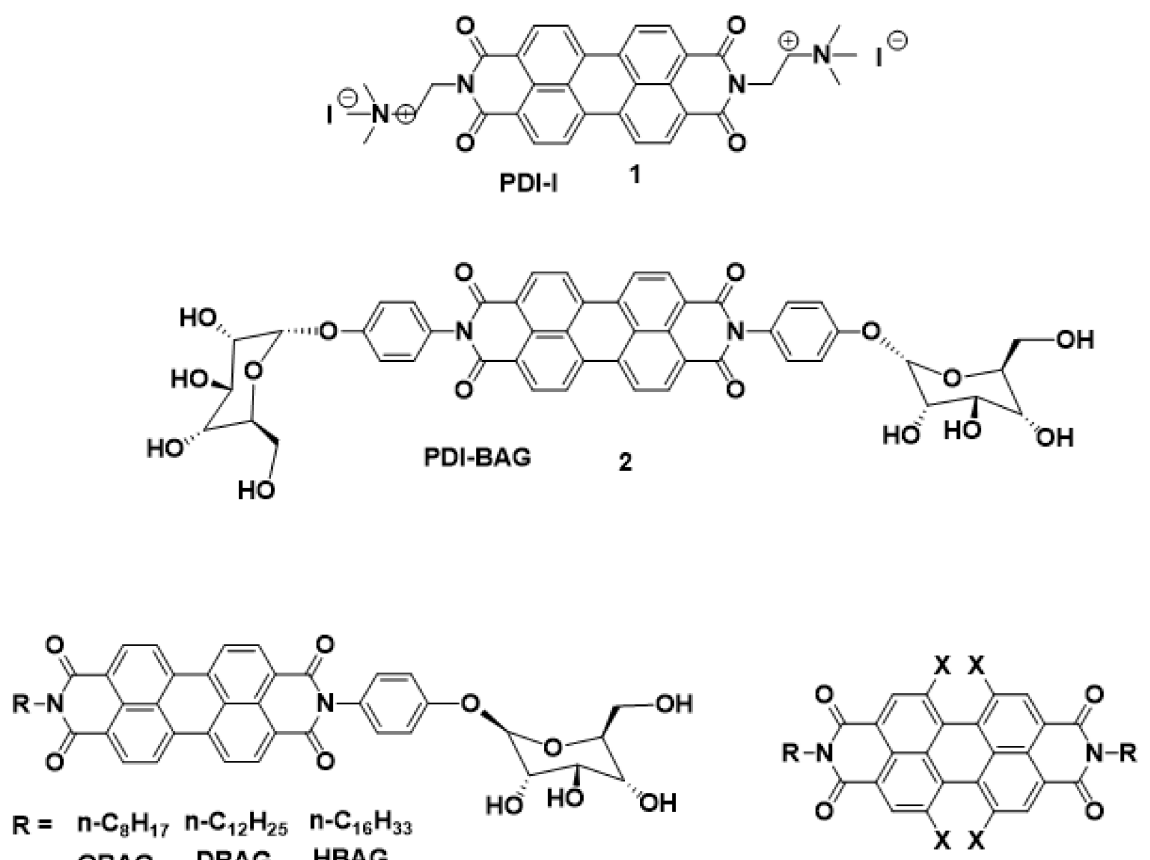

OBAG DBAG HBAG

3
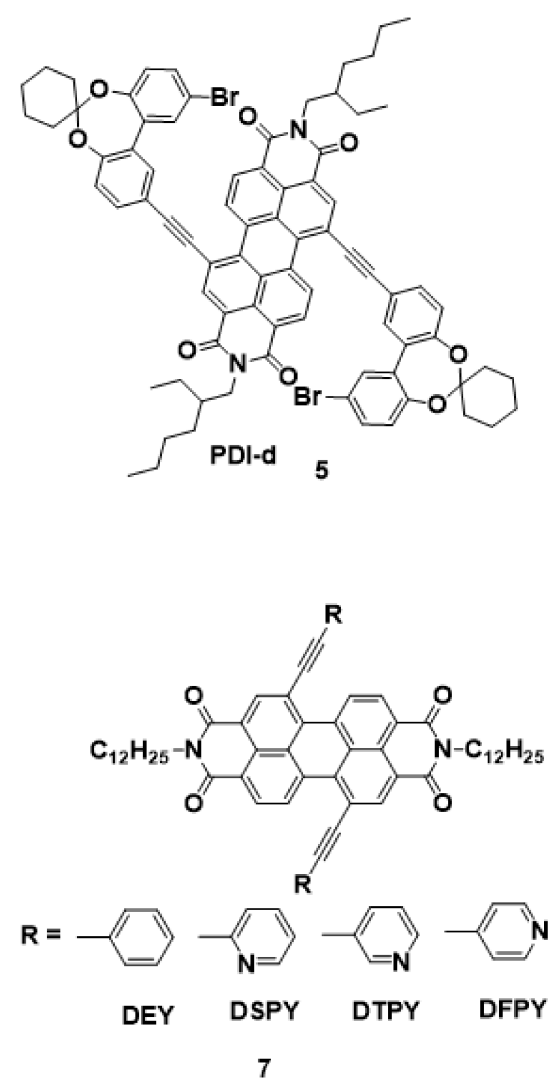

Figure 10. Cont.
$P D I-C 12: X=H ; R=$ $\mathrm{PDI}-\mathrm{ClC} 12: \mathrm{X}=\mathrm{Cl} ; \mathrm{R}=$ PDI-CIC4F7 : $\mathrm{X}=\mathrm{Cl}$; $\mathrm{R}=\overbrace{2}^{\mathrm{C}^{\mathrm{C}_{2}}} \mathrm{C}^{\mathrm{C}_{2}} \mathrm{CF}_{3} \quad 4$
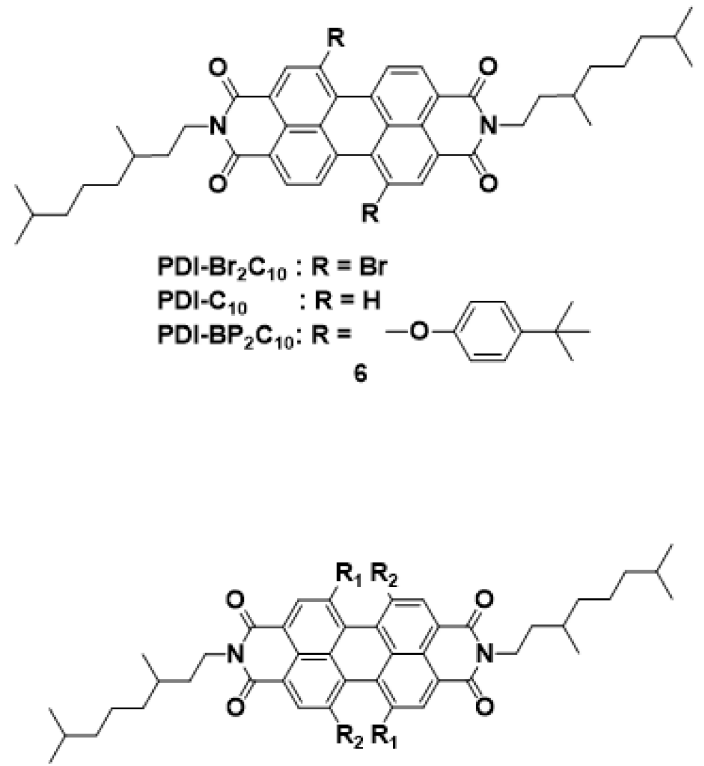

PDI-CNC $10: \mathbf{R}_{1}=\mathrm{CN} ; \mathbf{R}_{2}=\mathbf{H}$ PDI-ClC $10: \mathbf{R}_{1}=\mathbf{R}_{\mathbf{2}}=\mathbf{C l}$

8 

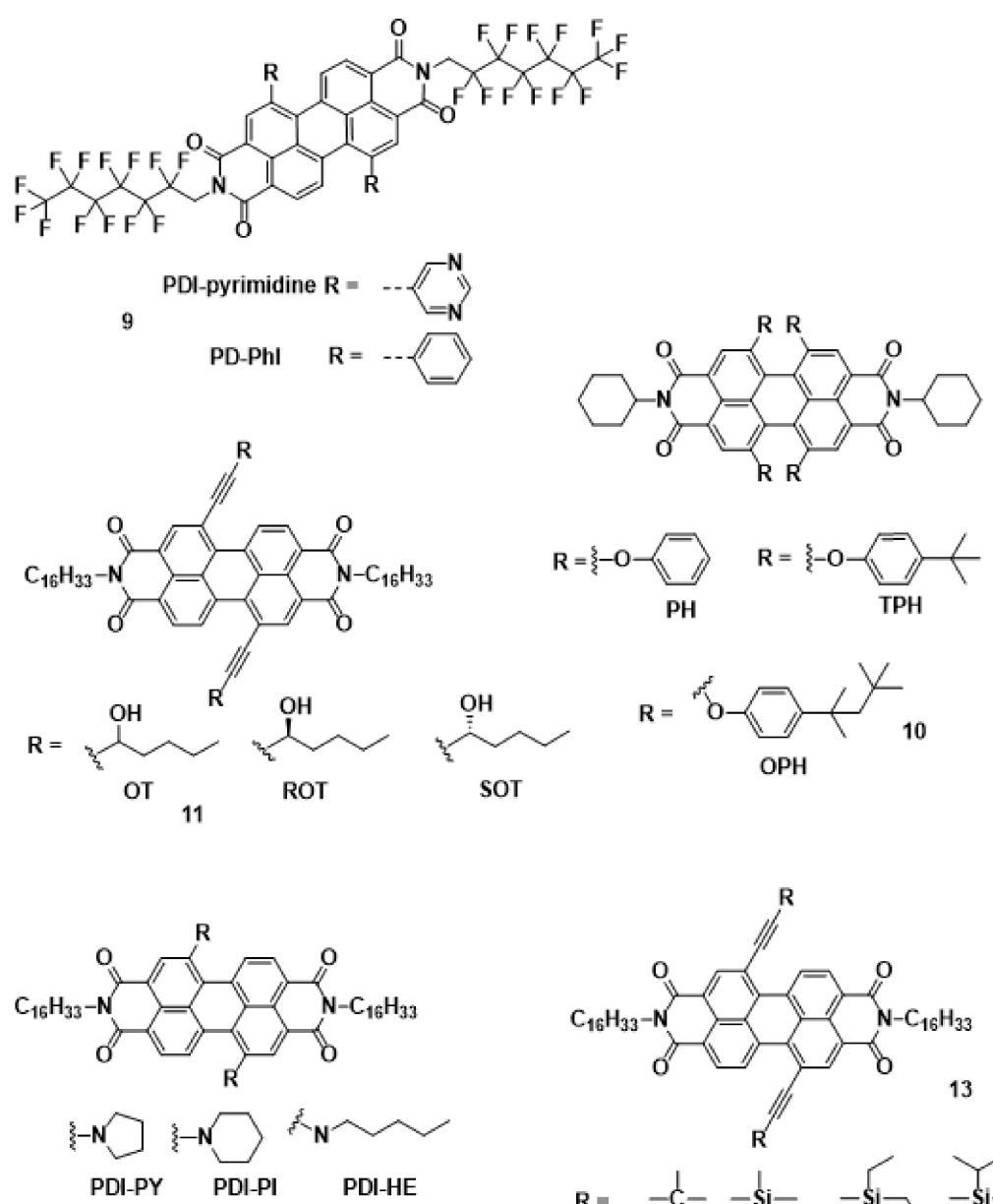

12
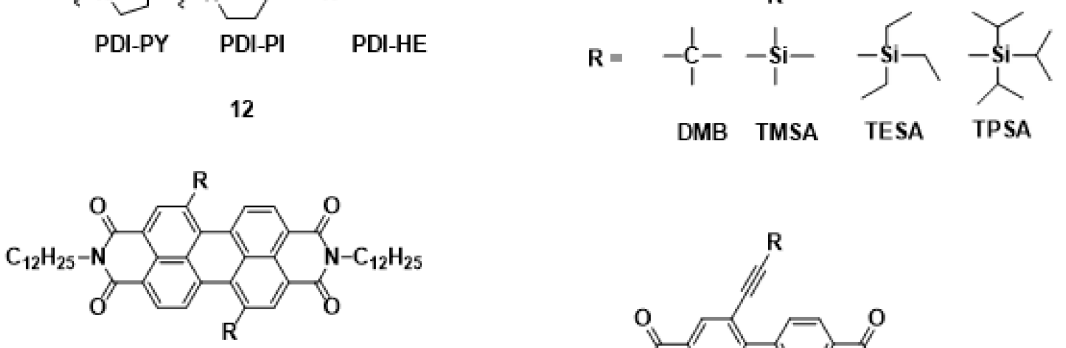

PDI- $\mathrm{C}_{12} \mathrm{R}=\mathrm{H}$

$\mathrm{PDI}-\mathrm{Br}_{2} \mathrm{C}_{12} \mathrm{R}=\mathrm{Br}$

$\mathrm{PDI}-\mathrm{CN}_{2} \mathrm{C}_{12} \mathrm{R}=\mathrm{CN}$

14
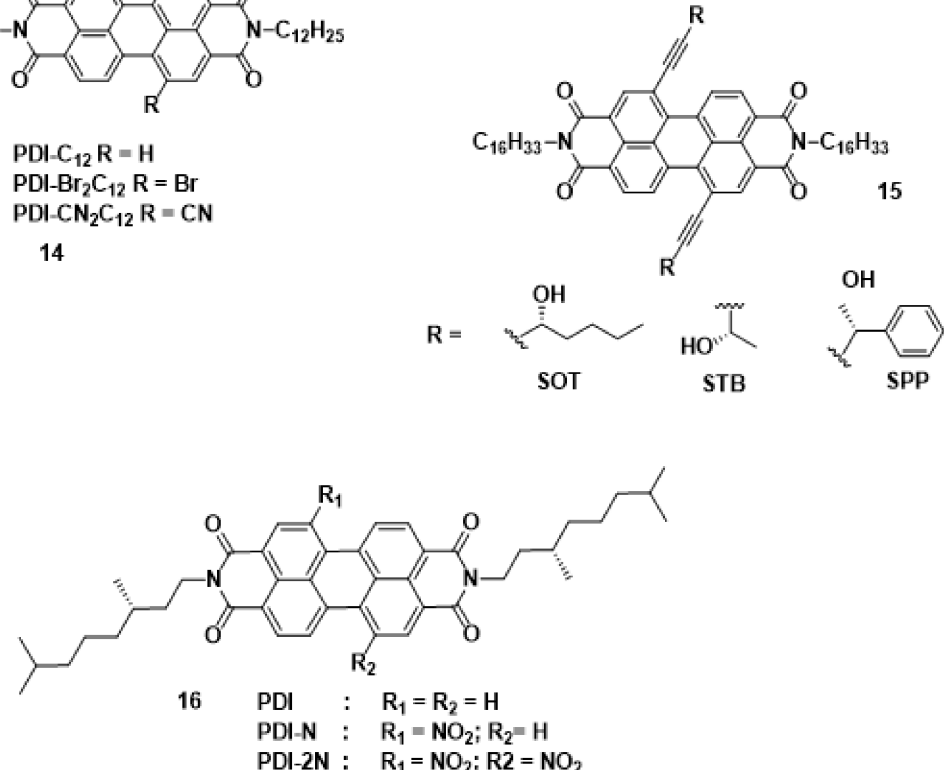

Figure 10. Cont. 

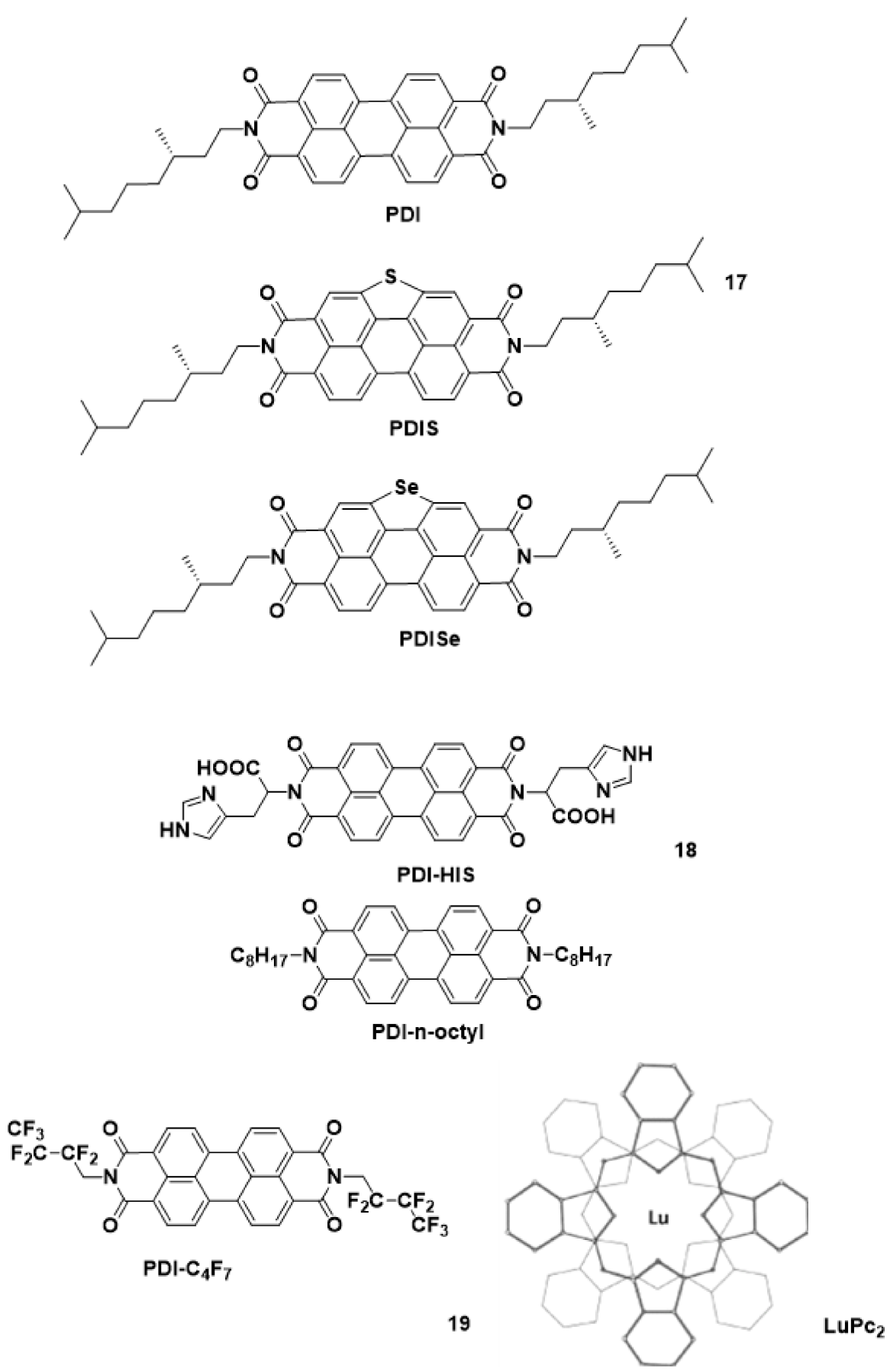
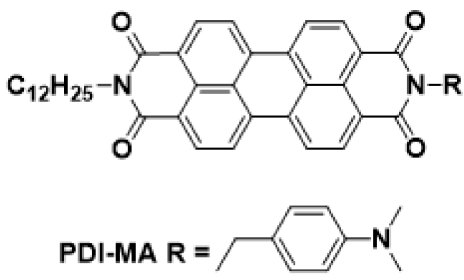

20

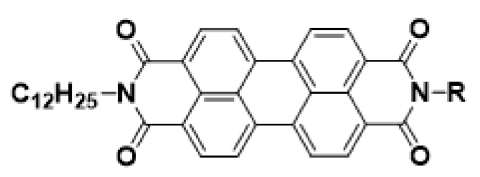

PDI-MP R $=$

21

Figure 10. Cont. 


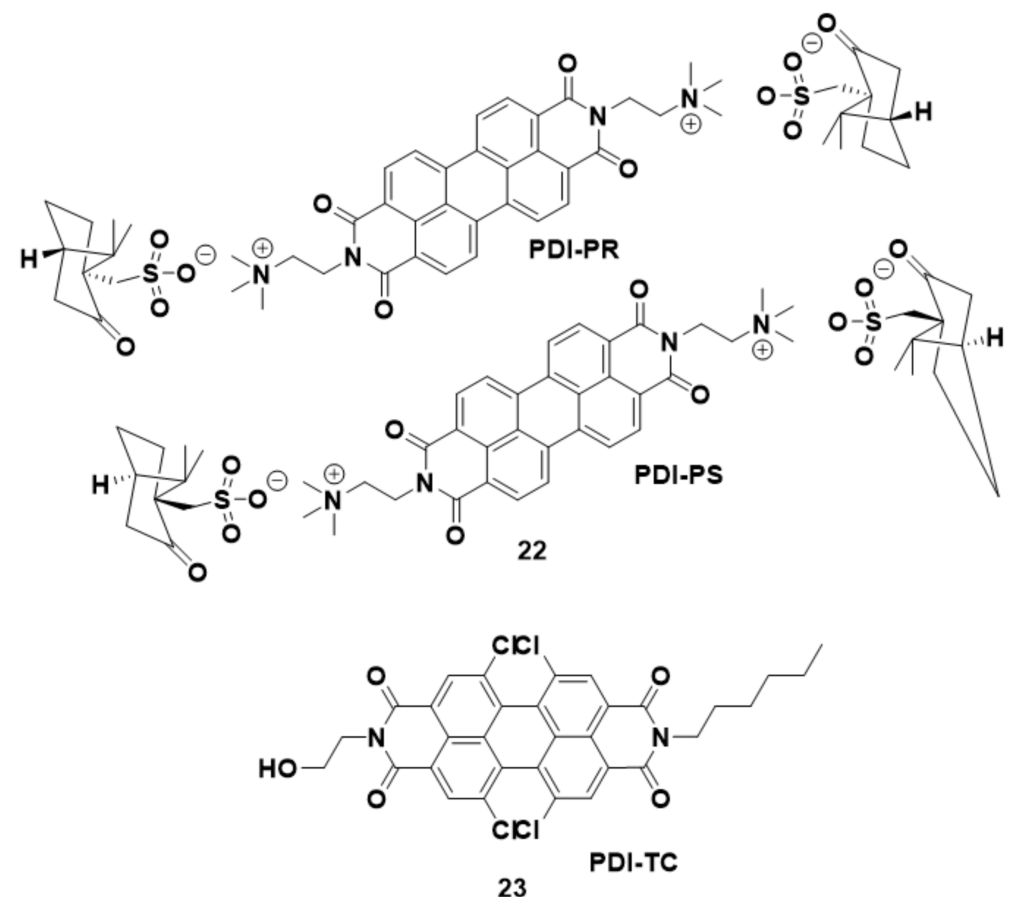

23

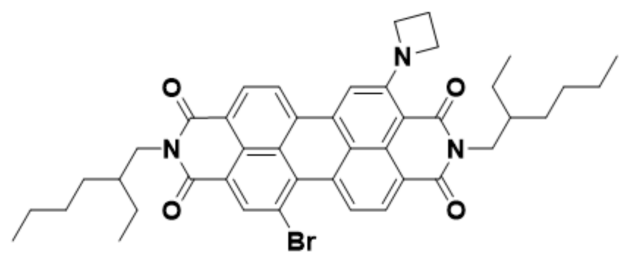

PDI-PB $\quad 24$

Figure 10. Chemical structures of the reported PDIs for hydrazine, ammonia, and other analyte sensing.

The final comparison group in this section looks at the alkylsilane-substituted PDIs, TMSA, TESA, and TPSA (structure 13; Figure 10) [35], in which the 1,7-acetylene PDI core is substituted at the terminal acetylenic positions with the alkylsilanes. To understand the effect of silyl chains on the sensing performance of devices, another PDI derivative, DMB bearing simple isostructural carbon frameworks, was also synthesized. An investigation into the sensing performance of PDI derivatives towards hydrazine vapor exhibited an increased current of around four orders of magnitude for the better performing TPSA derivative and 20 times higher than the TESA derivative. All the sensors showed a similar response time of approximately $200 \mathrm{~s}$, which was better in comparison with the PDI-DEY-0 and PDI-DAG-based sensors. The authors intimated that from the sensing results, the sensing performance of these PDI-based sensors are independent on the surface morphologies and surface areas, and it can be attributed to the difference in stacking modes, torsional angle, and interplanar spacing, thus providing a consistent message to other studies. Again, the ordered layer structure appears to contribute to TPSA having an effective sensing performance. A similar face-to-face packing mode and torsional angle of DMB and TMSA led both the derivatives to show nearly the same sensing results, regardless of the differences in their interplanar spacing. However, a larger torsional angle and headto-tail aggregated modes with larger interplanar spacing induced less-efficient sensing results. This study suggests that the lengths and branched points of the alkylsilane on core areas have a consequential effect on the sensing behavior of PTDCI-based gas sensors.

From the above discussion, we can summarize that the specific design features that influence the sensing performance of the core-substituted PDI derivatives are mainly derived from the LUMO energy levels, activation energy, and torsional angles. Furthermore, 
surface morphology generally appears to have a weak influence on the sensing performance of core-substituted PDI-based sensors for alike systems when compared to the effect of LUMO energy levels, activation energy, and torsional angles. Of course, systems with a significant disruption of stacking perform worse. The stability of PDI-based sensors also appears to be improved by core-substitution with electron-withdrawing functional groups, thus enhancing the $n$-type properties. Moreover, these functionalities, i.e., functionalities that promote hydrogen binding and modulate torsion angles, interplanar spacing, band gap, and stacking modes, can also significantly impact sensing performance through cooperative effects.

\section{Ammonia Sensing}

Ammonia is a critical commodity chemical with extensive applications in fertilizers, synthetic fibers, drugs, generating ammonium salts, and the manufacturing of plastics, but it is a highly corrosive and poisonous gas that can be easily spread into the environment [97]. Moreover, ammonium salts such as ammonium nitrate $\left(\mathrm{NH}_{4} \mathrm{NO}_{3}\right)$ are found in various explosives and slowly dissociate to release trace amounts of ammonia that are critical to be detected and monitored to avoid accidents [98]. Though ammonia has applications in numerous research areas, its exposure in high concentrations is deadly to human health in its extreme, leading to prolonged effects based on edema and airway destruction through burning. The lower limit of human perception by smell is around 50 ppm for ammonia [24]. However, even underneath this limit, it is irritating to skin, eyes, and the respiratory system, thus leading to cough and nose/throat irritation [99]. The permissible limits of 25 ppm over an $8 \mathrm{~h}$ period and 35 ppm over a $10 \mathrm{~min}$ period have been recommended and legislated by Health and Safety Executive (HSE), London [100]. To date, PDI-based sensors have been developed as both resistive and amperometric devices for ammonia-sensing applications, as summarized in Table 1 . This is not surprising given the strong similarity between ammonia and hydrazine as a reducing gas, with a similar magnitude of nucleophilicity regardless of any quantification of the alpha-effect [101].

To illustrate the point, the three electron-deficient PDI derivatives-PDI-C 12, PDI$\mathrm{Br}_{2} \mathrm{C}_{12}$, and PDI-CN $\mathrm{C}_{12}$ (structure 14; Figure 10) - that differ by the nature of the bay substitution with $\mathrm{H}, \mathrm{Br}$, or $\mathrm{CN}$ were identified and trialed for sensing ammonia gas [21] as single crystalline micro/nanostructures. The micro/nanostructures of PDI- $\mathrm{C}_{12}, \mathrm{PDI}_{-} \mathrm{Br}_{2} \mathrm{C}_{12}$, and PDI-CN $\mathrm{C}_{2} \mathrm{C}_{12}$ were prepared by a precipitation method in a chloroform/methanol binary solution $(0.1 \mathrm{mg} / \mathrm{mL})$. SEM images showed that all PDI compounds in this series could self-assemble into one-dimensional micro/nanostructures despite the influence of the bay groups. PDI- $\mathrm{C}_{12}$ molecules showed ribbon-like structures (Figure 11a) with an average width of 1-2 $\mu \mathrm{m}$ and lengths up to tens of micrometers, PDI- $\mathrm{CN}_{2} \mathrm{C}_{12}$ also self-assembled into a belt like morphology (Figure 11c) with an average diameter of 200-400 nm, and $\mathrm{PDI}-\mathrm{Br}_{2} \mathrm{C}_{12}$ molecules showed self-assembled nanorods (Figure $11 \mathrm{~b}$ ) with a diameter of approximately 200-300 $\mathrm{nm}$ and a length up to tens of micrometers. The devices were fabricated with a simple resistive-type structure. Upon exposing the three sensors to $1 \%$ ammonia, the resistance of PDI-CN $\mathrm{C}_{12}$ nanobelts decreased quickly (50 s) to reach a stable value and demonstrated a good sensitivity (40\%) (Figure 11d). However, no notable variations were observed in the resistance of PDI- $\mathrm{C}_{12}$ micro belts and $\mathrm{PDI}-\mathrm{Br}_{2} \mathrm{C}_{12}$ nanorods. The applicability of the PDI- $\mathrm{CN}_{2} \mathrm{C}_{12}$ sensor under an ambient atmosphere was further studied. The results indicated that while the sensitivity reduced to $37 \%$ in the first $24 \mathrm{~h}$, a constant value of $37 \%$ was maintained after its exposure to air for seven days. The superior response to ammonia gas by PDI- $\mathrm{CN}_{2} \mathrm{C}_{12}$ was attributed to the difference in the reduction potentials as a result of the insertion of the strong electron-withdrawing nitrile group, which caused a significant increase in current upon exposure to ammonia. The low LUMO energy level $(-4.36 \mathrm{eV})$ and the higher-order arrangement in nanobelts made PDI- $\mathrm{CN}_{2} \mathrm{C}_{12}$ more sensitive and stable. Though the PDI- $\mathrm{CN}_{2} \mathrm{C}_{12}$-based sensor showed good sensitivity and quick response, but there was no investigation into the selectivity of the sensor. 

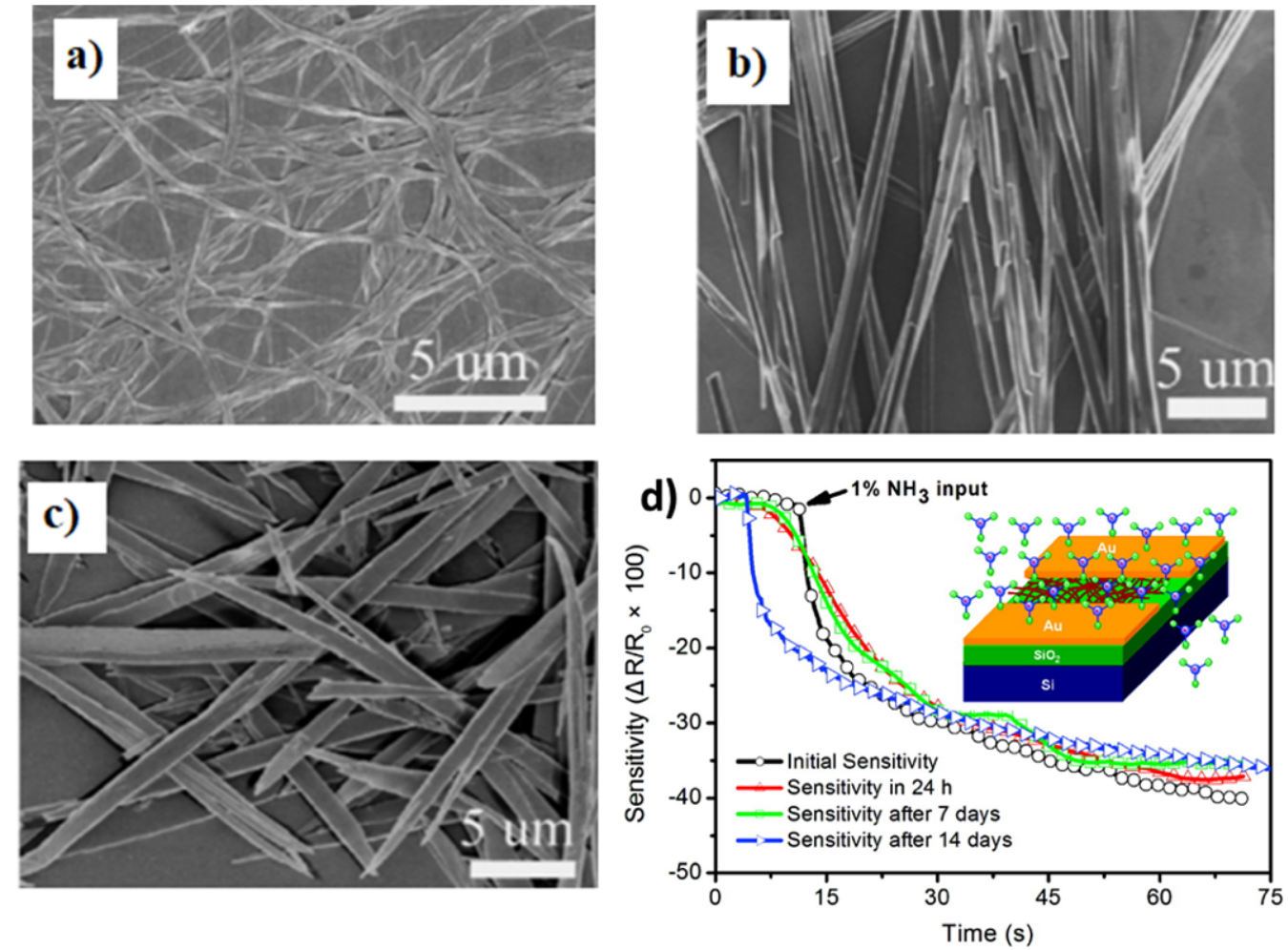

Figure 11. SEM images of (a) PDI- $\mathrm{C}_{12}$, (b) PDI- $\mathrm{Br}_{2} \mathrm{C}_{12}$, and (c) PDI-CN $\mathrm{C}_{2} \mathrm{C}_{12}$ illustrating subtle changes in the nanostructure as a result of bay substitutions. (d) Sensitivity curves of PDI- $\mathrm{CN}_{2} \mathrm{C}_{12}$ showing the stability of the system over time. Adapted with permission [21].

The effect of chirality-induced morphology through core-substitution on the sensing performance of PDIs [23] has been investigated through the three PDI derivatives-SOT, STB, and SPP (structure 15; Figure 10) - that differ by the position of hydroxy groups on the alkyl/aryl chains. All three PDI-based sensors showed quicker responses (>24 s), higher selectivities, and lower detection limits $(>1.51 \mathrm{ppm})$ towards ammonia than the PDI- $\mathrm{CN}_{2} \mathrm{C}_{12}$-based sensor [21]. Among these derivatives, SPP exhibited the highest sensitivity $(4.5 \%)$, the lowest LOD $(0.48 \mathrm{ppm})$, and the quickest response and recovery times (17 and $6 \mathrm{~s}$, respectively) (Figure 12d), mainly attributed to its lower LUMO energy level $(-4.13 \mathrm{eV})$ and uniform crystalline structure (Figure 12c). SOT showed a poor sensing performance with a response of $0.9 \%$ due to its highest LUMO level $(-4.06 \mathrm{eV})$ and poor crystallinity (Figure 12a). To explore the selectivity of the prepared sensors, all the sensors were exposed to ammonia (100 ppm), ethylamine, butylamine, diethylamine, triethylamine, dibutylamine, aniline, 2,4-dimethylaniline, and cyclohexylamine at a concentration of $1000 \mathrm{ppm}$. Interestingly, compared with other amines, all three sensors showed the highest selectivity towards ammonia, as shown in Figure 12e.

Two PDI derivatives bearing $\mathrm{NO}_{2}$ groups-PDI-N and PDI-2N (structure 16; Figure 10) -were prepared to further investigate the effect of reduction potential and the LUMO energy level on the sensitivity and stability of PDI-based sensors [86] for ammonia against a model PDI system. Among these derivatives, the PDI-2N-based sensor presented the smallest detection limit of $2 \mathrm{ppm}$, which was attributed to its reduction potential of $-0.36 \mathrm{eV}$, and the greatest ambient stability as a result of its low LUMO level of $-4.35 \mathrm{eV}$. However, the large torsional angle $\left(17.30^{\circ}\right)$ and interplanar spacing $(3.64 \AA)$ reduced the $\pi-\pi$ orbital overlap between the adjacent PDI-2N molecules, thus suppressing mobility and consequently moderating sensitivity-leading to an important design principle. A more positive reduction potential and ability for modest $\pi-\pi$ orbital overlap made the PDI-N device more sensitive $(6.6 \%)$ than PDI (1\%) and PDI-2N (5.6\%) devices. It was postulated that a negative reduction potential of $-0.73 \mathrm{eV}$ caused a lack of charge carrier density and 
induced an inferior sensing performance of the PDI sensor, although the structure of this device showed the highest $\pi-\pi$ orbital overlap. The experimental results suggested that the detection limit and ambient stability are closely related to the reduction potential and LUMO energy level.
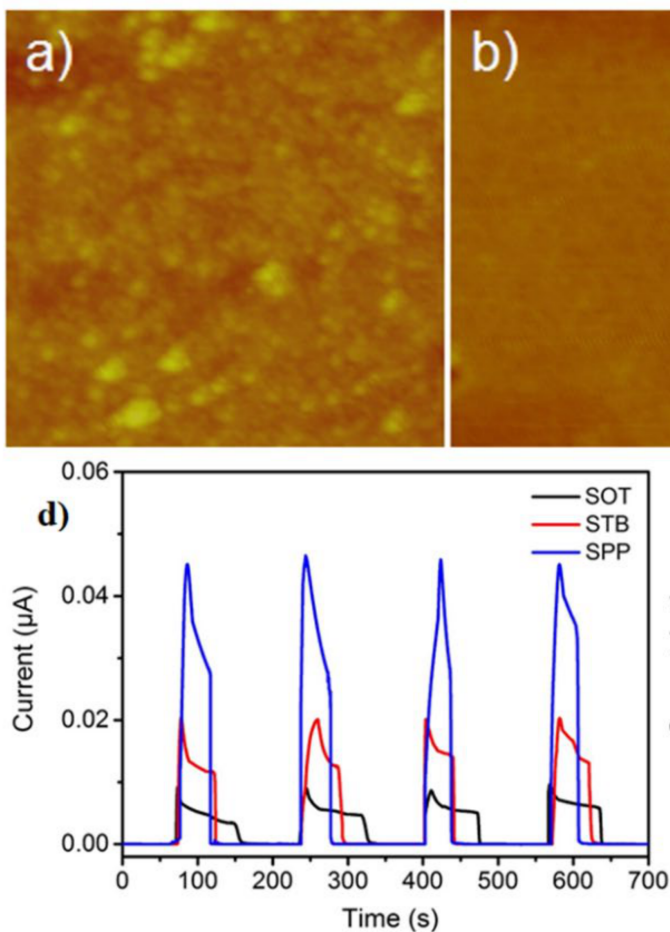
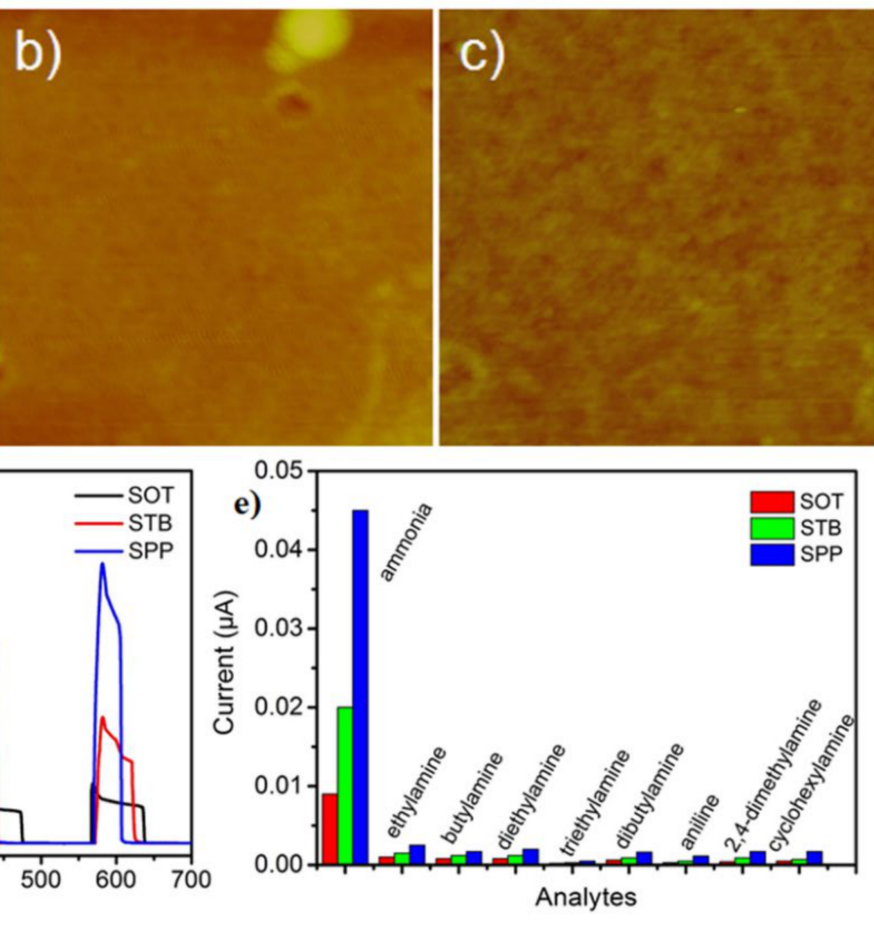

Figure 12. AFM images of (a) SOT, (b) STB, and (c) SPP thin films $(2 \times 2 \mu \mathrm{m})$ illustrating a similar morphology. (d) Dynamic current change of SOT, STB, and SPP devices in ammonia (100 ppm). (e) Current change for SOT, STB, and SPP devices exposed to numerous amine analytes. Adapted with permission [23].

The effect of chalcogenide inclusion on the sensing properties of PDIs has also been explored through the small series of PDI, PDIS, and PDISe (structure 17; Figure 10), where PDIS and PDISe derivatives represent the inclusion of sulfur (S) and selenium (Se) heterocycles, respectively, to the bay positions [87]. The sensing response of PDI, PDIS, and PDISe to $100 \mathrm{ppm}$ of ammonia gas was studied by using the two-probe method. Interestingly, when exposed to $100 \mathrm{ppm}$ of ammonia gas, the sulfur derivative showed an increase in current magnitude compared to the carbocyclic PDI, while the selenide showed a decrease compared to the same PDI. The PDIS ultimately showed the best sensing performance, with response magnitudes of 1.5 and 3 times higher than PDI and PDISe, respectively. The high response was mainly attributed to the electron donation from ammonia through donor-acceptor complexation towards perylene, followed by effective long-range electron transport via $\pi-\pi$ delocalization that led to current variations. The small rotational angle and the large $\pi-\pi$ overlap of vicinal PDIS cores were also attributed to improved electron mobility and the improvement in the sensing performance.

While much variation has occurred on the core of PDI, there are some examples to sense ammonia using functionalization at the imide nitrogens [24]. In a particular example, histidine moieties were attached to produce PDI-HIS, the sensing ability of which was compared to a bis( $n$-octyl)PDI (structure 18; Figure 10). The fabricated amperometric-type sensors were kept in a chamber, and various amounts of ammonia (2-100 ppm) were injected into the test chamber. The PDI-HIS-based sensor showed enhanced performance when compared with PDI- $n$-octyl-based sensor. A significant response (3500\%) to $100 \mathrm{ppm}$ of ammonia was recorded for PDI-HIS with a concomitant LOD of $0.56 \mathrm{ppm}$. To evaluate the selectivity of the PDI-HIS-based sensor, similar sensing experiments were also car- 
ried out using various analytes and different volatile organic solvents, including hexane, acetone, ethyl acetate, isopropanol, ethanol, methanol, and chloroform, together with ammonia. Interestingly, the response to $1000 \mathrm{ppm}$ of common organic analytes was less in comparison to $200 \mathrm{ppm}$ of ammonia (Figure 14a,b), cementing this as a good example of an organic-based sensor. By increasing the humidity, the sensitivity was shown to decrease, which could have been due to the weak adsorption/diffusion of ammonia gas on the sensor surface (Figure 13c). The effect of film thickness on the sensitivity of PDI-HIS was also investigated. Three sensors with different film thicknesses $(30,60$, and $100 \mathrm{~nm}$ ) were prepared and studied for their sensing response towards $100 \mathrm{ppm}$ of ammonia (Figure 13e,d). It was confirmed that the sensitivity rose by three times with slight increase in the response/recovery time (from 1 to $4 \mathrm{~s}$ ) when the film thickness was increased from 30 to $60 \mathrm{~nm}$; however, there did not appear to be a linear relationship between humidity and sensitivity. Upon a further increase in film thickness from 60 to $100 \mathrm{~nm}$, the sensitivity marginally increased and was greatly offset by the larger increase to the response/recovery times ( $26 \mathrm{~s} / 16 \mathrm{~s}$, respectively). The slow response in a thicker film is not uncommon and may be ascribed to the need for the diffusion of a large number of ammonia molecules into the film surface and their entrapment upon release. The lower redox potential of PDI-HIS, together with the presence of ionizable groups at the imide positions made the PDI-HIS-based sensors more efficient when compared with the sensors based on PDI-n-octyl.
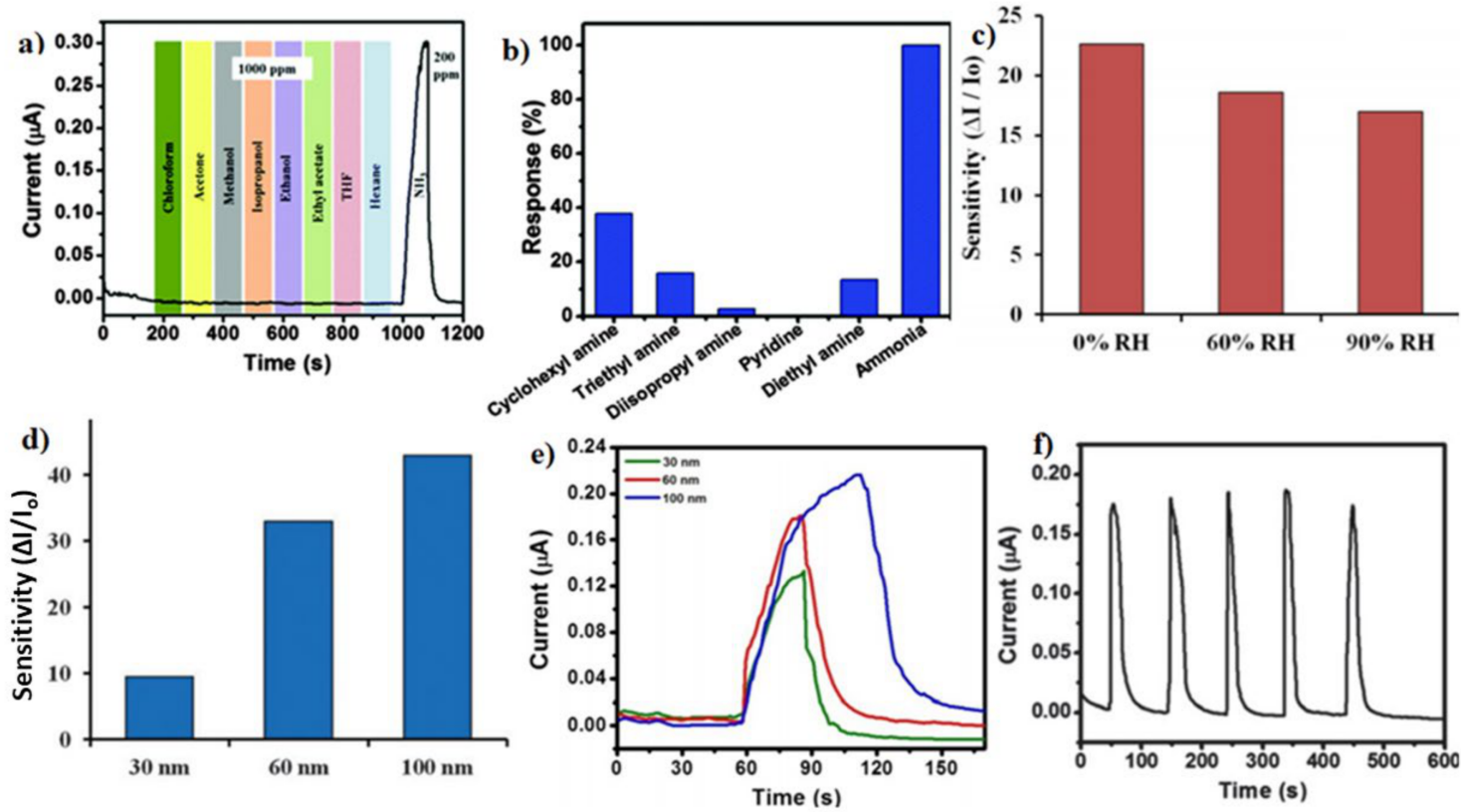

Figure 13. Response of a PDI-HIS sensor towards vapor of various common types of (a) organic solvents and (b) amines. Concentrations of ammonia and other analytes used were 200 and 1000 ppm, respectively. (c) Sensitivity of PDI-HIS at $0 \%$, $60 \%$, and $90 \%$ relative humidity levels. (d) Effect of film thickness on sensitivity of the sensor. (e) Current-time response observed in three devices with different film thicknesses upon exposure to $100 \mathrm{ppm}$ of ammonia. (f) Recyclability study with 100 ppm of ammonia. Adapted with permission [24].

While much of the discussion has investigated changes to active materials as opposed to the nature of the sensor device, there is a literature example of a prepared molecular semiconductor-doped insulator (MSDI) heterojunctions for ammonia sensing [88]. A fluorinated PDI derivative, $\mathrm{C}_{4} \mathrm{~F}_{7}-\mathrm{PDI}$, as an $n$-type material (bottom layer of the device), and lutetium bisphthalocyanine, $\mathrm{LuPc}_{2}$, as a $p$-type semiconductor (top layer), were used in the preparation of the MSDI heterojunction (structure 19, Figure 10). The heterojunction response to ammonia was compared to that from a sensor based solely on $\mathrm{LuPc}_{2}$. In stark contrast to each other, exposure to ammonia increased the current for the MSDI-based 
sensor, whereas the same exposure caused a decrease in the current of $\mathrm{LuPc}_{2}$-based sensor, thus illustrating a simple logic based 'ON' vs. 'OFF,' or 'bright' vs. 'dim,' response. The $\mathrm{C}_{4} \mathrm{~F}_{7}$-PDI/LuPc $2(50 \mathrm{~nm} / 50 \mathrm{~nm}) \mathrm{MSDI}$ showed a modest response to ammonia with a sensitivity of up $33 \%$ to 100 ppm of ammonia at $50 \%$ of relative humidity compared to the control.

From the above discussion, there appears to be unique design features that positively influence the sensing performance of PDI-based sensors for ammonia by optimizing the reduction potential, optimizing the thickness of the sensing layer, and attaching a particular functional group that can enhance hydrogen bonding. Furthermore, the reduction potential, LUMO energy level, crystal structure, and $\pi-\pi$ stacking can drastically affect the LOD, sensitivity, and stability of PDI-based sensors. Additionally, the judicial choice of functionality to either the core or imide positions needs further exploration because these changes have been shown to dramatically improve the sensitivity and selectivity of PDI-based sensors.

\section{Some Other Analyte-Sensing Applications}

PDI derivatives have also been developed and tested towards other analytes, including nitromethane, hydrogen peroxide, aniline, ethylenediamine, and trimethylamine [89-93]. The sensing performance of these sensors are also summarized in Table 1 in comparison to hydrazine and ammonia sensor performance.

Ultrathin nanoribbons formed from the amphiphilic electron donor-acceptor (D-A) PDI-MA (structure 20; Figure 10), comprising PDI as the backbone scaffold bearing dimethylaniline groups, were used for sensing various nitro-compounds such as nitromethane, nitrobenzene, 4-nitrotoluene, and 1-chloro-4-nitrobenzene (Figure 14a) [89]. The current of the sensor was decreased by about $65 \%$ upon exposure to a high concentration of nitromethane $(36,000 \mathrm{ppm})$. The nanoribbons also exhibited a fast response (10 s) with a quick recovery (75 s) (Figure 14c) due to the intrinsic volatility of the nitromethane. Various organic solvents and some reductive reagents, such as aniline, were also sensed. Some significant current variations were observed for organic solvents, such as hexane, toluene, and chloroform, thus suggesting a lower selectivity. It is postulated that this response is likely due to the solubility of PDI molecules in these solvents. PDI-MA nanofibers afford a mesh-like, highly porous surface that can offer a high surface area to the target analytes and the beneficial diffusion of the analytes through the 3D network.

$\mathrm{Wu}$ et al. [90] also synthesized nanoribbons (Figure 14b) of 1-methylpiperidinesubstituted PDIs (PDI-MP; structure 21; Figure 10). The nanoribbons were drop-cast over interdigitated electrodes and tested towards oxidizing hydrogen peroxide $\left(\mathrm{H}_{2} \mathrm{O}_{2}\right)$ vapor. When the PDI-MP sensor was exposed to 18.5 ppm of $\mathrm{H}_{2} \mathrm{O}_{2}$ vapor, a quick decrease in the current (50\% reduction) was recorded, as shown in Figure $14 \mathrm{~d}$. The sensor also displayed a quick response of $19.5 \mathrm{~s}$, which was attributed to the high surface area of nanoribbons, and the sensor was able to sense a concentration of 0.6 ppm of $\mathrm{H}_{2} \mathrm{O}_{2}$. The irreversible response towards $\mathrm{H}_{2} \mathrm{O}_{2}$ vapor was ascribed to the strong surface binding of $\mathrm{H}_{2} \mathrm{O}_{2}$ and the permanent oxidation of the 1-methylpiperidine group by $\mathrm{H}_{2} \mathrm{O}_{2}$.

The effect of the chiral auxiliary camphorsulfonic acid (CSA) on the sensing performance of PDI was also studied [91]. Two PDI derivatives, PR and PS (structure 22; Figure 10), were synthesized as active materials for the fabrication of amperometrictype sensors for sensing ammonia, ethylamine, butylamine, diethylamine, triethylamine, ethylenediamine, and hydrazine. The PDI-PR- and PDI-PS-based sensors displayed sensitivity $(1.5 \%$ and $17 \%$, respectively), quick response and recovery times $(9 / 7$ and $11 / 14 \mathrm{~s}$, respectively), and excellent selectivity towards ethylenediamine vapor with detection limits as low as 1.07 and 0.86 ppm, respectively. The PDI-PR-based sensor showed less sensitivity than the PDI-PR-based sensor due to the loss of $\pi-\pi$ interactions. The authors suggested that strong hydrogen bonding interactions between camphorsulfonic acid and ethylenediamine led to an enhanced sensing performance. 

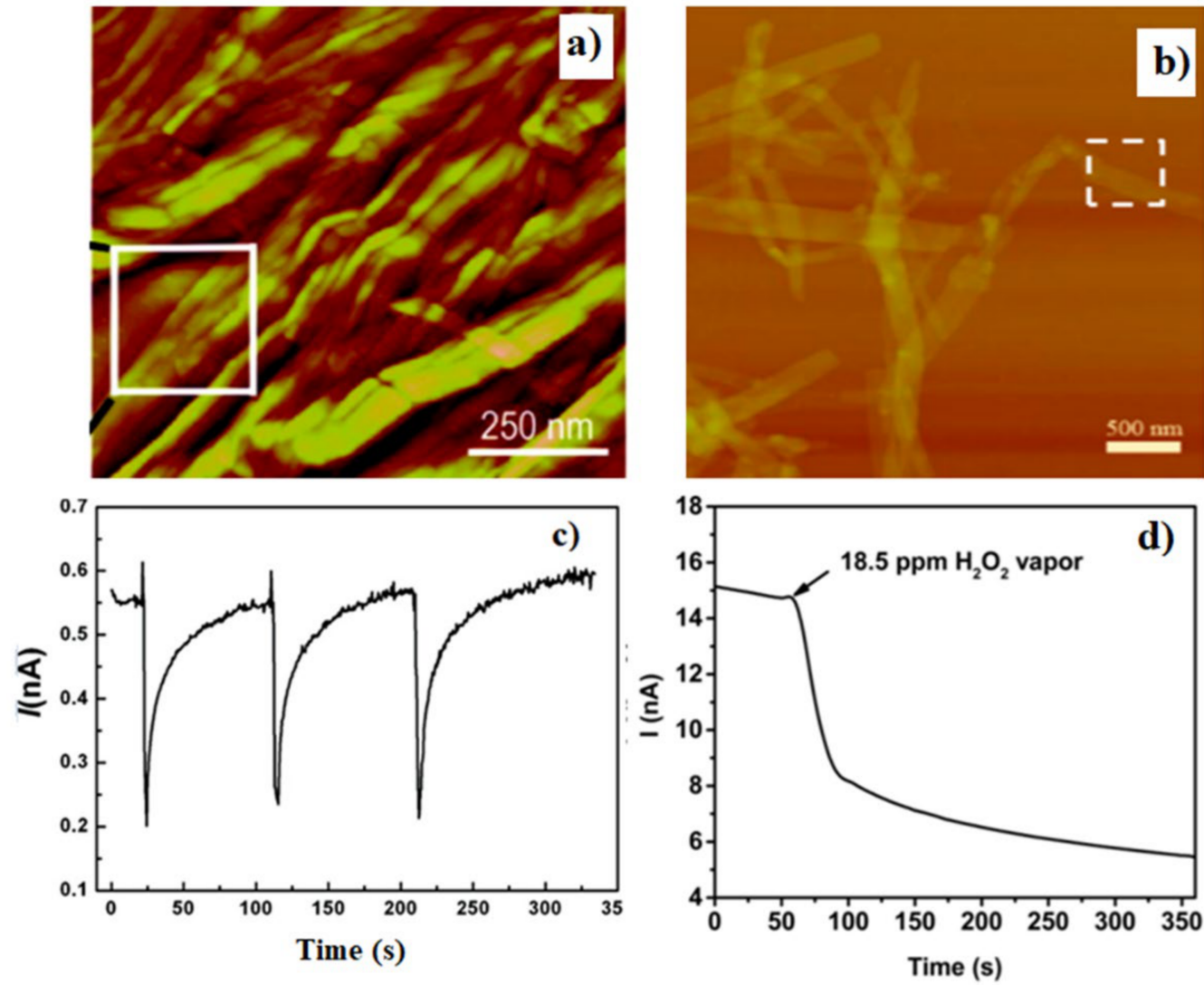

Figure 14. AFM images of (a) PDI-MA and (b) PDI-MP illustrating the ribbon-like morphology. Current change in PDI-MA nanoribbons in response to (c) nitromethane (36000 ppm) and (d) $\mathrm{H}_{2} \mathrm{O}_{2}$ (18.5 ppm). Adapted with permission [89,90].

Recently, Zhu et al. prepared a heterojunction of PDI and cadmium sulphide (CdS) (Figure 15a) to sense trimethylamine (TMA) vapor [92]. An amphiphilic PDI derivative, PDI-TC (structure 23; Figure 10), was synthesized and used to fabricate an amperometric gas sensor. The PDI-TC/CDS sensor showed a higher sensitivity (18\% at $10 \mathrm{ppm})$, a lower LOD (0.2 ppm), better stability and reproducibility (Figure 15b), and better selectivity towards TMA when compared with the sensor based on TC-PDI (no notable response at $10 \mathrm{ppm}$ ). The results clarified the synergistic effect between organic and inorganic materials and confirmed that $n-n$ heterojunctions are a viable approach to improve the sensing properties of TMA gas sensors.
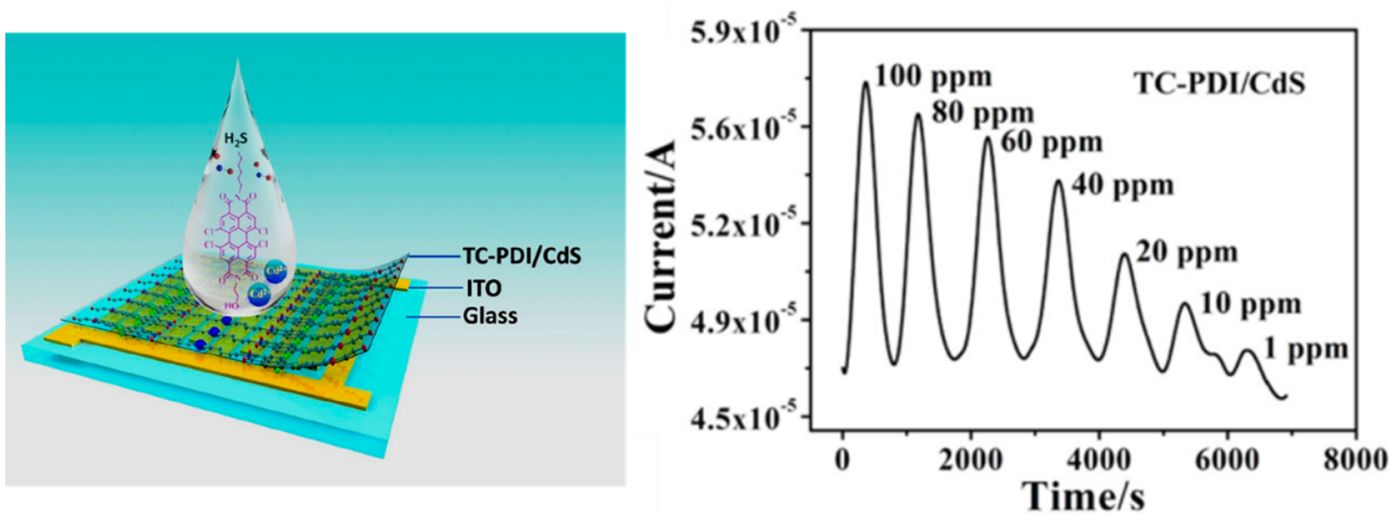

Figure 15. (a) Schematic diagram of TC-PDI/CdS (cadmium sulphide) heterojunction. (b) Response-recovery curves of TC-PDI/CdS sensor to different trimethylamine (TMA) concentrations. Adapted with permission [92]. 
The last example we discuss here is a novel, core PDI-PB derivative containing a core-substituted azacyclobutane (PDI-PB; structure 24; Figure 10) [93]. The self-assembled nano-network structure was prepared in chloroform and methanol, and it was used in the fabrication of resistive sensor for the detection of pyridine and its derivatives. The PDI-PB sensor showed a low LOD of $375 \mathrm{ppb}$, a quick response time (1 s), an excellent recyclability, and a high sensitivity (2200\%) towards 375 ppm of pyridine. The results obtained for the PDI-PB-based sensor suggests that a self-assembled nano-networked structure can improve the interaction between the target analyte and the sensing, leading to enhanced sensing performance, if designed appropriately.

\section{Conclusions and Future Outlook}

Through this review, we have demonstrated that organic-derived sensors have the capability of ushering new technology, and this is particularly true for the class of rylene aromatics of which PDI-based gas sensors are a part. Their strong evolution as active materials for electronic sensors or as part of heterojunction materials has been demonstrated to be effective in the sensing of hazardous and reducing gases such as hydrazine and ammonia. Compared to gas sensors based on inorganic materials, PDI-based gas sensors possess several advantages including solution-processability, mechanical flexibility, room-temperature operability, low power consumption, and portability. Through this series of highlighted compounds, it is worthwhile to mention that some general rules can be articulated to correlate sensing performance with the structural aspects or photophysical parameters of a given sensor family - in this case, prominent $n$-type semiconductor materials.

Overall, it is the redox properties of the active material, film morphology, and selfassembly of the PDI derivatives within the active layer that appear to play a significant role in gas-sensing performance. Most of the PDI derivatives with a uniform crystalline structure have demonstrated better sensitivity compared to derivatives with a poor crystalline structure. Therefore, single micro/nanostructures and ultra-thin nanotubes/nanorods have been continually employed to fabricate gas sensors with higher sensitivities, swifter responses, lower LOD values, and quick recovery times (a few seconds). By incorporating a variety of functional groups at the bay and imide positions of PDI, a number of novel materials have been developed to fabricate gas sensors with enhanced sensitivity, selectivity, and stability. The core substitutions of PDIs with different electron-donating and electron-withdrawing groups have also been shown to provide a significant impact on the sensitivity and stability of a given sensor as the electron-donating/withdrawing groups decrease the LUMO energy level and the reduction potential, which allows for the efficient transport of electrons by reducing the charge injection barrier to enhance the performance of a sensor. This is one of the main reasons why the core-substituted PDIs show a high sensitivity and better stability.

Though the development of PDI-based sensors is noteworthy, there are a number of design issues that need to be resolved for the mass-uptake of PDI-based sensors. Firstly, there are conflicts among some electrical properties of the chemical sensors such that while stronger interactions between the target analytes and sensors lead to superior sensitivity, they also confine the recovery to the initial state. The selectivity of a specific gas in a mixture of gases is still not resolved, but it is likely to be enhanced through other technologies including membranes and size-exclusion phenomena. The sensing mechanism of most of the PDI-based sensors is based on either the chemical or physical adsorption of target analytes. Several analytes can be adsorbed on the PDI's active layers to give similar resistance/conductance changes. For example, the adsorption of a reducing gas, including ammonia and hydrazine, increases the conductivity of PDI sensors. Consequently, different analytes may cause the same sensing response. The functionalization of PDI with different functional groups, e.g., - $\mathrm{COOH},-\mathrm{OH},-\mathrm{F},-\mathrm{Br}$, and $-\mathrm{NH}_{2}$, can be considered as a suitable method to resolve this issue. Functionalization will enhance the sensing performance by improving the hydrogen bonding or dipole-dipole interaction between the PDI's active layer and the target gas. However, functionalization may affect the sensor sensitivity and 
response/recovery time; hence, a balance must be considered between selectivity and sensitivity. Stability is another issue for PDI-based sensors when compared with metal oxide-based sensors. Here, we have shown that stability can also be improved by core substitution with different functional groups.

Several other factors, such as film thickness, humidity, and temperature, may also influence the performance of PDI-based gas sensors in terms of sensitivity, stability, response and recovery time, and lifetime- -though these are controlled. It can be argued that reducing the thickness of a sensing layer is helpful for an analyte to adsorb more quickly and to provide a swifter response. Similarly, thicker films can provide more adsorption/diffusion sites for analytes, which can increase sensitivity. Thinner films can help to induce crystallinity, which in fact is advantageous for high charge carriers' mobility and, hence, for high-performing electrical gas sensors. Thermal evaporation techniques can simply tune the film thickness by controlling the deposition rate, and the prepared ultrathin film has a superior quality with low-density defects. However, the requirement of a particular vacuum apparatus increases manufacturing cost and confines commercial processing. A change in the humidity level may also affect the sensitivity of a PDI-based sensor towards various analytes, as would more saturated mixed gases containing compounds that might act as good solvents for the active layer compound. For example, there have been reports that increasing the humidity level decreases the sensitivity towards ammonia vapor [24]. This is mainly due to the fact that there is a strong competition between the ammonia and water molecules to diffuse/adsorb through the sensing layer. Likewise, other reports have indicated that increasing the humidity level increases the sensitivity towards hydrazine vapor $[50,81]$. These reports reason that high humidity can be conductive for the hydration of hydrazine, and, thus, the active layer of PDIs will adsorb more hydrazine.

It is apparent that the influence of these factors on PDI-based electrical gas sensors has been rarely investigated. Thus, the effect of these factors on sensing performance needs a systematic study. The challenges moving forward might be overcome using other members of the rylene family - either smaller, more functionalizable and processable members or larger more aggregatable derivatives. We hope this review assists the readers in a judicial choice of strategy with which to affect significant advances in this novel field.

Author Contributions: Original draft preparation: S.A.; review, suggestions, and editions: A.G., M.S., and S.J.L. All authors have read and agreed to the published version of the manuscript.

Funding: We would like to gratefully acknowledge support from the Australian Research Council's Discovery Grant Scheme through DP170104477 and DP170102145. The authors acknowledge the funding support from the Faculty of Science, Engineering and Technology, Swinburne University of Technology. S Ali acknowledges PhD scholarship under the Swinburne Postgraduate Research Award (SUPRA) program.

Institutional Review Board Statement: Not applicable.

Informed Consent Statement: Not applicable.

Data Availability Statement: Data sharing not applicable.

Acknowledgments: We would like to gratefully Mohammed A. Jameel for his help in formatting the graphs and figures.

Conflicts of Interest: The authors declare no conflict of interests.

\section{References}

1. Zandi, A.; Gilani, A.; Koohsorkhi, J. An optimized resistive CNT-based gas sensor with a novel configuration by top electrical contact. Diam. Relat. Mater. 2019, 93, 224-232. [CrossRef]

2. Sun, J.; Chang, J.; Zhang, Q.; Xie, Y.; Zhang, Z.; Feng, Y.; Sun, H. Recent progress in research on TDLAS fiber optical gas sensor performance improvement. In Second Symposium on Novel Technology of X-Ray Imaging; International Society for Optics and Photonics: Bellingham, WA, USA, 2019; Volume 11068, p. 110680L.

3. Suma, M.; Prasad, M.; Gaddam, V.; Rajanna, K.; Nayak, M. Development of a Novel Acoustic Sensor using Sputtered ZnO Thin Film. J. Pure Appl. Ind. Phys. 2019, 9, 1-7. 
4. Gao, L.; Zhang, J.; Zhai, L.; Wang, X.; Fan, L.; Hu, T. Gas adsorption and fluorescent sensing properties of two porous lanthanide metal-organic frameworks based on 3, 5-bis (2-carboxy-phenoxy)-benzoic acid. Polyhedron 2019, 165, 171-176. [CrossRef]

5. Shafiei, M.; Spizzirri, P.G.; Arsat, R.; Yu, J.; du Plessis, J.; Dubin, S.; Kaner, R.B.; Kalantar-Zadeh, K.; Wlodarski, W. Platinum/graphene nanosheet/SiC contacts and their application for hydrogen gas sensing. J. Phys. Chem. C 2010, 114, 13796-13801. [CrossRef]

6. Shafiei, M.; Sadek, A.Z.; Yu, J.; Latham, K.; Breedon, M.; McCulloch, D.; Kalantar-zadeh, K.; Wlodarski, W. A hydrogen gas sensor based on Pt/nanostructured WO3/SiC Schottky diode. Sens. Lett. 2011, 9, 11-15. [CrossRef]

7. Shafiei, M.; Bradford, J.; Khan, H.; Piloto, C.; Wlodarski, W.; Li, Y.; Motta, N. Low-operating temperature NO2 gas sensors based on hybrid two-dimensional SnS2-reduced graphene oxide. Appl. Surf. Sci. 2018, 462, 330-336. [CrossRef]

8. Jian, Y.; Hu, W.; Zhao, Z.; Cheng, P.; Haick, H.; Yao, M.; Wu, W. Gas sensors based on chemi-resistive hybrid functional nanomaterials. Nano-Micro Lett. 2020, 12, 1-43. [CrossRef]

9. Chen, S.; Gao, N.; Bunes, B.R.; Zang, L. Tunable nanofibril heterojunctions for controlling interfacial charge transfer in chemiresistive gas sensors. J. Mater. Chem. C 2019, 7, 13709-13735. [CrossRef]

10. Adgate, J.L.; Goldstein, B.D.; McKenzie, L.M. Potential public health hazards, exposures and health effects from unconventional natural gas development. Environ. Sci. Technol. 2014, 48, 8307-8320. [CrossRef]

11. Wang, C.; Bunes, B.R.; Xu, M.; Wu, N.; Yang, X.; Gross, D.E.; Zang, L. Interfacial donor-acceptor nanofibril composites for selective alkane vapor detection. ACS Sens. 2016, 1, 552-559. [CrossRef]

12. Andre, R.S.; Sanfelice, R.C.; Pavinatto, A.; Mattoso, L.H.; Correa, D.S. Hybrid nanomaterials designed for volatile organic compounds sensors: A review. Mater. Des. 2018, 156, 154-166. [CrossRef]

13. Van Hieu, N.; Thuy, L.T.B.; Chien, N.D. Highly sensitive thin film NH3 gas sensor operating at room temperature based on SnO2/MWCNTs composite. Sens. Actuators B 2008, 129, 888-895. [CrossRef]

14. Koo, W.-T.; Jang, J.-S.; Kim, I.-D. Metal-Organic Frameworks for Chemiresistive Sensors. Chem 2019, 5, 1938-1963. [CrossRef]

15. Lee, J.-H. Gas sensors using hierarchical and hollow oxide nanostructures: Overview. Sens. Actuators B 2009, 140, 319-336. [CrossRef]

16. Wang, Y.; Gong, Q.; Miao, Q. Structured and Functionalized Organic Semiconductors for Chemical and Biological Sensors Based on Organic Field Effect Transistors. Mater. Chem. Front. 2020, 4, 3505-3520. [CrossRef]

17. Jones, T.; Bott, B.; Thorpe, S. Fast response metal phthalocynanine-based gas sensors. Sens. Actuators 1989, 17, 467-474. [CrossRef]

18. Bohrer, F.I.; Colesniuc, C.N.; Park, J.; Ruidiaz, M.E.; Schuller, I.K.; Kummel, A.C.; Trogler, W.C. Comparative gas sensing in cobalt, nickel, copper, zinc, and metal-free phthalocyanine chemiresistors. J. Am. Chem. Soc. 2008, 131, 478-485. [CrossRef]

19. Jiang, Y.; Huang, W.; Zhuang, X.; Tang, Y.; Yu, J. Thickness modulation on semiconductor towards high performance gas sensors based on organic thin film transistors. MSEB 2017, 226, 107-113. [CrossRef]

20. Dong, Z.; Kong, X.; Wu, Y.; Zhang, J.; Chen, Y. High-sensitive room-temperature $\mathrm{NO}_{2}$ sensor based on a soluble n-type phthalocyanine semiconductor. Inorg. Chem. Commun. 2017, 77, 18-22. [CrossRef]

21. Huang, Y.; Fu, L.; Zou, W.; Zhang, F.; Wei, Z. Ammonia sensory properties based on single-crystalline micro/nanostructures of perylenediimide derivatives: Core-substituted effect. J. Phys. Chem. C 2011, 115, 10399-10404. [CrossRef]

22. Huang, Y.; Fu, L.; Zou, W.; Zhang, F. Probing the effect of substituted groups on sensory properties based on single-crystalline micro/nanostructures of perylenediimide dyes. New J. Chem. 2012, 36, 1080-1084. [CrossRef]

23. Zhang, S.; Wang, X.; Huang, Y.; Zhai, H.; Liu, Z. Ammonia sensing properties of perylene diimides: Effects of core-substituted chiral groups. Sens. Actuators B 2018, 254, 805-810. [CrossRef]

24. Kalita, A.; Hussain, S.; Malik, A.H.; Subbarao, N.V.; Iyer, P.K. Vapor phase sensing of ammonia at the sub-ppm level using a perylene diimide thin film device. J. Mater. Chem. C 2015, 3, 10767-10774. [CrossRef]

25. Nketia-Yawson, B.; Noh, Y.-Y. Organic thin film transistor with conjugated polymers for highly sensitive gas sensors. Macromol. Res. 2017, 25, 489-495. [CrossRef]

26. Li, B.; Lambeth, D.N. Chemical sensing using nanostructured polythiophene transistors. Nano Lett. 2008, 8, 3563-3567. [CrossRef]

27. Tiwari, S.; Singh, A.K.; Joshi, L.; Chakrabarti, P.; Takashima, W.; Kaneto, K.; Prakash, R. Poly-3-hexylthiophene based organic field-effect transistor: Detection of low concentration of ammonia. Sens. Actuators B 2012, 171, 962-968. [CrossRef]

28. Dai, M.-Z.; Lin, Y.-L.; Lin, H.-C.; Zan, H.-W.; Chang, K.-T.; Meng, H.-F.; Liao, J.-W.; Tsai, M.-J.; Cheng, H. Highly sensitive ammonia sensor with organic vertical nanojunctions for noninvasive detection of hepatic injury. Anal. Chem. 2013, 85, 3110-3117. [CrossRef]

29. Yang, Z.; Zhuang, X.; Han, S.; Yu, J. Hole-transporting polymer dilution driven high performance organic transistor-based $\mathrm{NO}_{2}$ gas sensor. Mater. Lett. 2019, 236, 285-288. [CrossRef]

30. Bertoni, C.; Naclerio, P.; Viviani, E.; Dal Zilio, S.; Carrato, S.; Fraleoni-Morgera, A. Nanostructured P3HT as a Promising Sensing Element for Real-Time, Dynamic Detection of Gaseous Acetone. Sensors 2019, 19, 1296. [CrossRef]

31. Dutta, G.K.; Kasthuri, S.; Marappan, G.; Jayaraman, S.V.; Sivalingam, Y.; Di Natale, C.; Nutalapati, V. Aggregation behavior in naphthalene-appended diketopyrrolopyrrole derivatives and its gas adsorption impact on surface potential. J. Mater. Chem. C 2019, 7, 9954-9965. [CrossRef]

32. Song, R.; Wang, Z.; Zhou, X.; Huang, L.; Chi, L. Gas-Sensing Performance and Operation Mechanism of Organic $\pi$-Conjugated Materials. Chempluschem 2019, 84, 1222-1234. [CrossRef] [PubMed] 
33. Zhao, Y.; Guo, Y.; Liu, Y. 25th anniversary article: Recent advances in n-type and ambipolar organic field-effect transistors. Adv. Mater. 2013, 25, 5372-5391. [CrossRef] [PubMed]

34. Huang, Y.; Zhang, W.; Wang, J.; Fu, L.; Shi, J. Electron-withdrawing groups induced remarkable changes in sensory property based on single micro/nanostructure of perylenediimide derivatives. Mater. Chem. Phys. 2015, 151, 93-98. [CrossRef]

35. Huang, Y.; Zhang, W.; Zhai, H.; Li, C. Alkylsilane-functionalized perylenediimide derivatives with differential gas sensing properties. J. Mater. Chem. C 2015, 3, 466-472. [CrossRef]

36. Kozma, E.; Catellani, M.J.D. Perylene diimides based materials for organic solar cells. Dyes Pigment. 2013, 98, 160-179. [CrossRef]

37. Smith, H.M. High Performance Pigments; Wiley Online Library: Hoboken, NJ, USA, 2002.

38. Li, C.; Wonneberger, H. Perylene imides for organic photovoltaics: Yesterday, today, and tomorrow. Adv. Mater. 2012, 24, 613-636. [CrossRef] [PubMed]

39. Zhan, X.; Facchetti, A.; Barlow, S.; Marks, T.J.; Ratner, M.A.; Wasielewski, M.R.; Marder, S.R. Rylene and related diimides for organic electronics. Adv. Mater. 2011, 23, 268-284. [CrossRef]

40. Zang, L.; Che, Y.; Moore, J.S. One-dimensional self-assembly of planar $\pi$-conjugated molecules: Adaptable building blocks for organic nanodevices. Acc. Chem. Res. 2008, 41, 1596-1608. [CrossRef]

41. Würthner, F. Perylene bisimide dyes as versatile building blocks for functional supramolecular architectures. Chem. Commun. 2004, 1564-1579. [CrossRef]

42. Huang, C.; Barlow, S.; Marder, S.R. Perylene-3, 4, 9, 10-tetracarboxylic acid diimides: Synthesis, physical properties, and use in organic electronics. J. Org. Chem. 2011, 76, 2386-2407. [CrossRef]

43. Schmidt, R.; Ling, M.M.; Oh, J.H.; Winkler, M.; Könemann, M.; Bao, Z.; Würthner, F. Core-Fluorinated Perylene Bisimide Dyes: Air Stable n-Channel Organic Semiconductors for Thin Film Transistors with Exceptionally High On-to-Off Current Ratios. Adv. Mater. 2007, 19, 3692-3695. [CrossRef]

44. Chen, S.; Slattum, P.; Wang, C.; Zang, L. Self-assembly of perylene imide molecules into 1D nanostructures: Methods, morphologies, and applications. Chem. Rev. 2015, 115, 11967-11998. [CrossRef] [PubMed]

45. Zang, L. Interfacial donor-acceptor engineering of nanofiber materials to achieve photoconductivity and applications. Acc. Chem. Res. 2015, 48, 2705-2714. [CrossRef] [PubMed]

46. Ego, C.; Marsitzky, D.; Becker, S.; Zhang, J.; Grimsdale, A.C.; Müllen, K.; MacKenzie, J.D.; Silva, C.; Friend, R.H. Attaching perylene dyes to polyfluorene: Three simple, efficient methods for facile color tuning of light-emitting polymers. J. Am. Chem. Soc. 2003, 125, 437-443. [CrossRef]

47. Chen, Z.; Zheng, Y.; Yan, H.; Facchetti, A. Naphthalenedicarboximide-vs perylenedicarboximide-based copolymers. Synthesis and semiconducting properties in bottom-gate n-channel organic transistors. J. Am. Chem. Soc. 2009, 131, 8-9. [CrossRef]

48. Huang, Y.; Quan, B.; Wei, Z.; Liu, G.; Sun, L. Self-assembled organic functional nanotubes and nanorods and their sensory properties. J. Phys. Chem. C 2009, 113, 3929-3933. [CrossRef]

49. Huang, Y.; Yuan, R.; Zhou, S. Gas phase-based growth of highly sensitive single-crystal rectangular micro-and nanotubes. J. Mater. Chem. 2012, 22, 883-888. [CrossRef]

50. Liu, H.; Wang, H.; Liu, G.; Pu, S.; Zhang, H. Ultrasensitive sensing of hydrazine vapor at sub-ppm level with pyrimidinesubstituted perylene diimide film device. Tetrahedron 2019, 75, 1988-1996. [CrossRef]

51. Huang, Y.; Hu, J.; Kuang, W.; Wei, Z.; Faul, C.F. Modulating helicity through amphiphilicity—tuning supramolecular interactions for the controlled assembly of perylenes. Chem. Commun. 2011, 47, 5554-5556. [CrossRef]

52. Huang, Y.; Yan, Y.; Smarsly, B.; Wei, Z.; Faul, C. Helical supramolecular aggregates, liquid crystallinity and nanofibers of a perylenebisimide-chiral surfactant complex via ionic self-assembly. J. Mater. Chem. 2009, 19, 2356-2362. [CrossRef]

53. Schmidt, R.D.; Oh, J.H.; Sun, Y.-S.; Deppisch, M.; Krause, A.-M.; Radacki, K.; Braunschweig, H.; Könemann, M.; Erk, P.; Bao, Z. High-performance air-stable n-channel organic thin film transistors based on halogenated perylene bisimide semiconductors. $J$. Am. Chem. Soc. 2009, 131, 6215-6228. [CrossRef] [PubMed]

54. Delgado, M.C.R.; Kim, E.-G.; Filho, D.t.A.d.S.; Bredas, J.-L. Tuning the charge-transport parameters of perylene diimide single crystals via end and/or core functionalization: A density functional theory investigation. J. Am. Chem. Soc. 2010, 132, 3375-3387. [CrossRef] [PubMed]

55. Molinari, A.S.; Alves, H.; Chen, Z.; Facchetti, A.; Morpurgo, A.F. High electron mobility in vacuum and ambient for PDIF-CN2 single-crystal transistors. J. Am. Chem. Soc. 2009, 131, 2462-2463. [CrossRef] [PubMed]

56. Hu, J.; Kuang, W.; Deng, K.; Zou, W.; Huang, Y.; Wei, Z.; Faul, C.F. Self-Assembled Sugar-Substituted Perylene Diimide Nanostructures with Homochirality and High Gas Sensitivity. Adv. Energy Mater. 2012, 22, 4149-4158. [CrossRef]

57. Huang, L.; Wang, Z.; Zhu, X.; Chi, L. Electrical gas sensors based on structured organic ultra-thin films and nanocrystals on solid state substrates. Nanoscale Horiz. 2016, 1, 383-393. [CrossRef]

58. Huang, Y.; Zhang, W.; Wang, J.; Wei, Z. Probing the sensory property of perylenediimide derivatives in hydrazine gas: Coresubstituted aromatic group effect. ACS Appl. Mater. Interfaces 2014, 6, 9307-9313. [CrossRef]

59. Muzikante, I.; Parra, V.; Dobulans, R.; Fonavs, E.; Latvels, J.; Bouvet, M. A novel gas sensor transducer based on phthalocyanine heterojunction devices. Sensors 2007, 7, 2984-2996. [CrossRef]

60. Bohrer, F.I.; Sharoni, A.; Colesniuc, C.; Park, J.; Schuller, I.K.; Kummel, A.C.; Trogler, W.C. Gas sensing mechanism in chemiresistive cobalt and metal-free phthalocyanine thin films. J. Am. Chem. Soc. 2007, 129, 5640-5646. [CrossRef]

61. Bakker, E.; Telting-Diaz, M. Electrochemical sensors. Anal. Chem. 2002, 74, 2781-2800. [CrossRef] 
62. Deshpande, R. Capacitors: Technology and Trends; Tata McGraw-Hill Education: New York, NY, USA, 2012.

63. Sinclair, I. Passive Components for Circuit Design; Elsevier: Amsterdam, The Netherlands, 2000.

64. Zhang, C.; Chen, P.; Hu, W. Organic field-effect transistor-based gas sensors. Chem. Soc. Rev. 2015, 44, 2087-2107. [CrossRef]

65. Teradal, N.L.; Marx, S.; Morag, A.; Jelinek, R. Porous graphene oxide chemi-capacitor vapor sensor array. J. Mater. Chem. C 2017, 5, 1128-1135. [CrossRef]

66. Yao, M.S.; Tang, W.X.; Wang, G.E.; Nath, B.; Xu, G. MOF thin film-coated metal oxide nanowire array: Significantly improved chemiresistor sensor performance. Adv. Mater. 2016, 28, 5229-5234. [CrossRef] [PubMed]

67. Dai, J.; Ogbeide, O.; Macadam, N.; Sun, Q.; Yu, W.; Li, Y.; Su, B.-L.; Hasan, T.; Huang, X.; Huang, W. Printed gas sensors. Chem. Soc. Rev. 2020, 49, 1756-1789. [CrossRef]

68. Lundström, K.; Shivaraman, M.; Svensson, C. A hydrogen-sensitive Pd-gate MOS transistor. J. Appl. Phys. 1975, 46, 3876-3881. [CrossRef]

69. Torsi, L.; Dodabalapur, A.; Sabbatini, L.; Zambonin, P. Multi-parameter gas sensors based on organic thin-film-transistors. Sens. Actuators B 2000, 67, 312-316. [CrossRef]

70. Feliciano, G.T.; Sanz-Navarro, C.; Coutinho-Neto, M.D.; Ordejón, P.; Scheicher, R.H.; Rocha, A.R. Capacitive DNA detection driven by electronic charge fluctuations in a graphene nanopore. Phys. Rev. Appl. 2015, 3, 034003. [CrossRef]

71. Cui, H.; Cheng, C.; Lin, X.; Wu, J.; Chen, J.; Eda, S.; Yuan, Q. Rapid and sensitive detection of small biomolecule by capacitive sensing and low field AC electrothermal effect. Sens. Actuators B 2016, 226, 245-253. [CrossRef]

72. Tahir, M.; Sayyad, M.H.; Clark, J.; Wahab, F.; Aziz, F.; Shahid, M.; Munawar, M.A.; Chaudry, J.A.J.S.; Chemical, A.B. Humidity, light and temperature dependent characteristics of $\mathrm{Au} / \mathrm{N}-\mathrm{BuHHPDI} / \mathrm{Au}$ surface type multifunctional sensor. Sens. Actuators $B$ 2014, 192, 565-571. [CrossRef]

73. Yassine, O.; Shekhah, O.; Assen, A.H.; Belmabkhout, Y.; Salama, K.N.; Eddaoudi, M. H2S Sensors: Fumarate-Based fcu-MOF Thin Film Grown on a Capacitive Interdigitated Electrode. Angew. Chem. 2016, 128, 16111-16115. [CrossRef]

74. Lou, Z.; Li, L.; Wang, L.; Shen, G. Recent progress of self-powered sensing systems for wearable electronics. Small 2017, 13, 1701791. [CrossRef]

75. Altenberend, U.; Oprea, A.; Barsan, N.; Weimar, U. Contribution of polymeric swelling to the overall response of capacitive gas sensors. Anal. Bioanal. Chem. 2013, 405, 6445-6452. [CrossRef] [PubMed]

76. Pokhrel, S.; Simion, C.; Quemener, V.; Barsan, N.; Weimar, U. Investigations of conduction mechanism in $\mathrm{Cr}_{2} \mathrm{O}_{3}$ gas sensing thick films by ac impedance spectroscopy and work function changes measurements. Sens. Actuators B 2008, 133, 78-83. [CrossRef]

77. Neri, G. First fifty years of chemoresistive gas sensors. Chemosensors 2015, 3, 1-20. [CrossRef]

78. Bochenkov, V.; Sergeev, G. Sensitivity, selectivity, and stability of gas-sensitive metal-oxide nanostructures. Metal Oxide Nanostruct. Their Appl. 2010, 3, 31-52.

79. Torsi, L.; Magliulo, M.; Manoli, K.; Palazzo, G. Organic field-effect transistor sensors: A tutorial review. Chem. Soc. Rev. 2013, 42, 8612-8628. [CrossRef] [PubMed]

80. Huang, Y.; Wang, J.; Wei, Z. Modulating supramolecular helicity and electrical conductivity of perylene dyes through an achiral alkyl chain. Chem. Commun. 2014, 50, 8343-8345. [CrossRef]

81. Wang, J.; He, E.; Liu, X.; Yu, L.; Wang, H.; Zhang, R.; Zhang, H. High performance hydrazine vapor sensor based on redox mechanism of twisted perylene diimide derivative with lower reduction potential. Sens. Actuators B 2017, 239, 898-905. [CrossRef]

82. Huang, Y.; Wang, J.; Fu, L.; Kuang, W.; Shi, J. Effect of core-substituted groups on sensing properties based on single micro/nanorod of perylenediimide derivatives. Sens. Actuators B 2013, 188, 411-416. [CrossRef]

83. Liu, X.; Zhai, H.; Zhang, S.; Fu, J.; Huang, Y. Impact of alkyl chain and bay-phenoxy unit on the sensing performance of perylenediimide derivatives. Sens. Actuators B 2017, 243, 500-506. [CrossRef]

84. Li, C.; Zhai, H.; Liu, X.; Zhang, W.; Huang, Y. Effect of stereoisomerism of the alkyl chain on the gas sensing properties based on perylene dyes. J. Mater. Chem. C 2015, 3, 2778-2782. [CrossRef]

85. Huang, Y.; Zhang, S.; Zhong, G.; Li, C.; Liu, Z.; Jin, D. Highly responsive hydrazine sensors based on donor-acceptor perylene diimides: Impact of electron-donating groups. Phys. Chem. Chem. Phys. 2018, 20, 19037-19044. [CrossRef] [PubMed]

86. Wang, X.; Li, C.; Huang, Y.; Zhai, H.; Liu, Z.; Jin, D. Highly sensitive and stable perylene sensor for ammonia detection: A case study of structure-property relationships. Sens. Actuators B 2018, 275, 451-458. [CrossRef]

87. Deng, Q.; Zhou, E.; Huang, Y.; Qing, W.; Zhai, H.; Liu, Z.; Wei, Z. Chalcogen-substitution modulated supramolecular chirality and gas sensing properties in perylenediimides. Chem. Commun. 2019, 55, 4379-4382. [CrossRef] [PubMed]

88. Gaudillat, P.; Wannebroucq, A.; Suisse, J.-M.; Bouvet, M. Bias and humidity effects on the ammonia sensing of perylene derivative/lutetium bisphthalocyanine MSDI heterojunctions. Sens. Actuators B 2016, 222, 910-917. [CrossRef]

89. Che, Y.; Yang, X.; Liu, G.; Yu, C.; Ji, H.; Zuo, J.; Zhao, J.; Zang, L. Ultrathin n-type organic nanoribbons with high photoconductivity and application in optoelectronic vapor sensing of explosives. J. Am. Chem. Soc. 2010, 132, 5743-5750. [CrossRef]

90. Wu, N.; Wang, C.; Bunes, B.R.; Zhang, Y.; Slattum, P.M.; Yang, X.; Zang, L. Chemical self-doping of organic nanoribbons for high conductivity and potential application as chemiresistive sensor. ACS Appl. Mater. Interfaces 2016, 8, 12360-12368. [CrossRef]

91. Huang, Y.; Liu, X.; Wang, Q.; Fu, J.; Zhao, L.; Liu, Z.; Jin, D. Highly responsive ethylenediamine vapor sensor based on a perylenediimide-camphorsulfonic acid complex via ionic self-assembly. J. Mater. Chem. C 2017, 5, 7644-7651. [CrossRef]

92. Zhu, P.; Wang, Y.; Ma, P.; Li, S.; Fan, F.; Cui, K.; Ge, S.; Zhang, Y.; Yu, J. Low-Power and High-Performance Trimethylamine Gas Sensor Based on nn Heterojunction Microbelts of Perylene Diimide/CdS. Anal. Chem. 2019, 91, 5591-5598. [CrossRef] 
93. Liu, Q.; Zhao, C.; Shao, X.; Wang, W.; Ji, X. High sensitive pyridine chemiresistive sensors based on azacyclobutane modified perylene bisimide derivatives. Dyes Pigment. 2021, 185, 108902. [CrossRef]

94. Ye, H.; Chen, L.; Wang, X.; Lu, D. A highly sensitive fluorescent probe for hydrazine detection: Synthesis, characterisation and application in living cells. Int. J. Environ. Anal. Chem. 2019, 1-13. [CrossRef]

95. Wang, G.; Zhang, C.; He, X.; Li, Z.; Zhang, X.; Wang, L.; Fang, B. Detection of hydrazine based on Nano-Au deposited on Porous- $\mathrm{TiO}_{2}$ film. Electrochim. Acta 2010, 55, 7204-7210. [CrossRef]

96. U.E.P. Agency. Integrated Risk Information System (IRIS) on Benzene. 2002. Available online: http://yosemite.epa.gov/ sab / sabproduct.nsf/d21b76bff879fa0a8525735a00766807/d3bb75d4297ca46985257943005-22ace!OpenDocument (accessed on 8 October 2020).

97. Appl, M. Ammonia: Principles and industrial practice. Future 1999, 245, 12.

98. Pandey, S.; Goswami, G.K.; Nanda, K.K. Nanocomposite based flexible ultrasensitive resistive gas sensor for chemical reactions studies. Sci. Rep. 2013, 3, 2082. [CrossRef] [PubMed]

99. Wang, J.; Yang, P.; Wei, X. High-performance, room-temperature, and no-humidity-impact ammonia sensor based on heterogeneous nickel oxide and zinc oxide nanocrystals. ACS Appl. Mater. Interfaces 2015, 7, 3816-3824. [CrossRef] [PubMed]

100. Malins, C.; Doyle, A.; MacCraith, B.; Kvasnik, F.; Landl, M.; Šimon, P.; Kalvoda, L.; Lukaš, R.; Pufler, K.D.; Babusik, I. Personal ammonia sensor for industrial environments. J. Environ. Monit. 1999, 1, 417-422. [CrossRef] [PubMed]

101. Nigst, T.A.; Antipova, A.; Mayr, H. Nucleophilic reactivities of hydrazines and amines: The futile search for the $\alpha$-effect in hydrazine reactivities. J. Org. Chem. 2012, 77, 8142-8155. [CrossRef] [PubMed] 